\title{
Activation of Rod Input in a Model of Retinal Degeneration Reverses Retinal Remodeling and Induces Formation of Functional Synapses and Recovery of Visual Signaling in the Adult Retina
}

\author{
Tian Wang, ${ }^{1}$ Johan Pahlberg, ${ }^{2 \star}$ Jon Cafaro, ${ }^{3 *}$ - Rikard Frederiksen, ${ }^{2}$ A.J. Cooper, ${ }^{1}$ AAlapakkam P. Sampath, ${ }^{2}$ \\ (1)Greg D. Field, ${ }^{3}$ and $\odot$ Jeannie Chen ${ }^{1}$ \\ ${ }^{1}$ Zilkha Neurogenetic Institute, Department of Physiology and Neuroscience, Keck School of Medicine, University of Southern California, Los Angeles, \\ California 90089, 2Department of Ophthalmology, Stein Eye Institute, University of California, Los Angeles, California 90095, and ${ }^{3}$ Department of \\ Neurobiology, Duke University School of Medicine, Durham, North Carolina 27710
}

A major cause of human blindness is the death of rod photoreceptors. As rods degenerate, synaptic structures between rod and rod bipolar cells disappear and the rod bipolar cells extend their dendrites and occasionally make aberrant contacts. Such changes are broadly observed in blinding disorders caused by photoreceptor cell death and are thought to occur in response to deafferentation. How the remodeled retinal circuit affects visual processing following rod rescue is not known. To address this question, we generated male and female transgenic mice wherein a disrupted cGMP-gated channel (CNG) gene can be repaired at the endogenous locus and at different stages of degeneration by tamoxifen-inducible cre-mediated recombination. In normal rods, light-induced closure of CNG channels leads to hyperpolarization of the cell, reducing neurotransmitter release at the synapse. Similarly, rods lacking CNG channels exhibit a resting membrane potential that was $\sim 10 \mathrm{mV}$ hyperpolarized compared to WT rods, indicating diminished glutamate release. Retinas from these mice undergo stereotypic retinal remodeling as a consequence of rod malfunction and degeneration. Upon tamoxifen-induced expression of CNG channels, rods recovered their structure and exhibited normal light responses. Moreover, we show that the adult mouse retina displays a surprising degree of plasticity upon activation of rod input. Wayward bipolar cell dendrites establish contact with rods to support normal synaptic transmission, which is propagated to the retinal ganglion cells. These findings demonstrate remarkable plasticity extending beyond the developmental period and support efforts to repair or replace defective rods in patients blinded by rod degeneration.

Key words: gene therapy; neural plasticity; neural transmission; photoreceptor cell death; retinal circuitry; retinal degeneration

Significance Statement

Current strategies for treatment of neurodegenerative disorders are focused on the repair of the primary affected cell type. However, the defective neurons function within a complex neural circuitry, which also becomes degraded during disease. It is not known whether rescued neurons and the remodeled circuit will establish communication to regain normal function. We show that the adult mammalian neural retina exhibits a surprising degree of plasticity following rescue of rod photoreceptors. The wayward dendrites of rod bipolar cells re-establish contact with rods to support normal synaptic transmission, which is propagated to the retinal ganglion cells. These findings support efforts to repair or replace defective rods in patients blinded by rod cell loss.

\section{Introduction}

Diseases that afflict sensory systems typically result from deficiencies within the sensory receptor cells themselves, ei- ther within sensory transduction or synaptic transmission (Bermingham-McDonogh and Reh, 2011). Deficits in visual processing are no exception, with the majority of blinding diseases 
(such as retinitis pigmentosa and age-related macular degeneration) result from the dysfunction or death of the primary input cells, the retinal rod and cone photoreceptors (Quartilho et al., 2016). Synaptic remodeling of retinal circuits, in particular between photoreceptor cells and their downstream neurons, occur early in retinal degeneration (Soto and Kerschensteiner, 2015). Remodeling of bipolar and horizontal cell dendrites is thought to occur in response to deafferentation (Marc and Jones, 2003). Changes that occur include homeostatic downregulation of synaptic structures, exuberant extension of dendritic processes, which sometimes contact off-target sites (Marc and Jones, 2003; Puthussery and Taylor, 2010), and even switching of postsynaptic receptor types from mGluR to iGluR expression (Chua et al., 2009). In genetically inherited forms of retinal degeneration, synaptic changes may already occur during a critical period of retinal development. It is not known how these changes in retinal circuitry may ultimately limit recovery of normal vision, although several approaches are being implemented to rescue dying photoreceptors using gene therapy, or replace them with stem cells (Scholl et al., 2016; Garg et al., 2017; Yao et al., 2018). To address this gap in knowledge, this study focuses on cellular plasticity in retinal circuits of young adult mice with rod degeneration, and how the synaptic structures and circuits that receive rod input respond to rod rescue.

We genetically engineered a mouse line in which rod function can be uniformly rescued via tamoxifen-induced cre-mediated recombination. The line was generated to lack expression of the cyclic nucleotide gated (CNG) channel $\beta-1$ subunit (CNGB1) because of an insertion of a neomycin cassette at the endogenous gene to disrupt expression (Wang and Chen, 2014; T. Wang et al., 2017). This mouse model recapitulates the effects of mutations in human $C N G B 1$ and $C N G A 1$ genes that cause autosomal recessive retinitis pigmentosa (Biel and Michalakis, 2007). Without the CNGB1 subunit, the CNG channels in rod outer segments fail to form normally functioning channels, which leads to a slow form of rod death that occurs over 4-6 months (Zhang et al., 2009; T. Wang et al., 2017), or longer (Hüttl et al., 2005). Importantly, the neomycin cassette is flanked by loxP sites, which allows for cremediated excision and the expression of CNGB1 from the endogenous locus. Thus, this mouse line provides an opportunity to introduce precisely a "cure" for the underlying genetic defect at different time points during degeneration.

We use this novel mouse line to determine the extent to which activating rod input in the degenerating retina allows recovery of the structure and function of well defined rod-driven retinal circuits in young adult mice. The lack of CNG channels caused stereotypic degenerative changes in the retina that included rhodopsin mislocalization, activation of Müller glia, and a reduction of presynaptic and postsynaptic proteins between rods and rod bipolar cells by as early as 4 weeks of age. Signal transmission from rods to rod bipolar cells was abrogated and sensitivity of retinal ganglion cells (RGCs) was reduced $\sim 100$-fold. Tamoxifen-induced restoration of $\mathrm{CNG}$ channel expression initiated at 4 weeks of age

\footnotetext{
mGluR6 antibody, Dr. C. Craft for providing the cone arrestin (ARR3) antibody, and Dr. S. Ruffins at the USC microscopy core for his help with confocal imaging.

The authors declare no competing financial interests.

*J.P. and J. Cafaro contributed equally to this work.

Correspondence should be addressed to Alapakkam P. Sampath at asampath@jsei.ucla.edu or Greg D. Field at field@neuro.duke.edu.

J. Pahlberg's present address: Photoreceptor Physiology Group, National Institute of Dental and Craniofacial Research, National Institutes of Health, Bethesda, MD 20892.

https://doi.org/10.1523/JNEUROSCI.2902-18.2019

Copyright $\odot 2019$ the authors
}

led to an expected recovery of rod photoreceptor function. Importantly, we show that initiation of rod input in the deafferented adult retina also induced a high degree of structural plasticity between rods and their primary postsynaptic partner, rod (ON) bipolar cells. Specifically, rod bipolar cell dendrites sprouted fine tips and mGluR6 clusters formed on these tips, which made new synapses with rods. This structural transformation resulted in near-normal light responses in both bipolar cells and RGCs, the output neurons of the retina. Our findings indicate substantial plasticity in the adult mammalian retina, suggesting favorable outcomes for interventions targeting the rescue of dysfunctional rods from death.

\section{Materials and Methods}

Generation of transgenic mice. The use of mice in these experiments was in accordance with the National Institutes of Health guidelines and the Institutional Animal Care and Use Committee of our respective universities. Targeting of the neoloxP to the Cngbl locus in mouse embryonic stem cells and generation of transgenic mice from verified stem cell clones were described previously (Chen et al., 2010). The CAGGCre-ER transgenic line, $\operatorname{Tg}\left(\mathrm{CAG}\right.$-cre/Esr $\left.1^{\star}\right) 5 \mathrm{Amc} / \mathrm{J}$, was obtained from The Jackson Laboratory and crossed with $\mathrm{Cngb} 1^{\text {neo/neo }}$ mice.

Tamoxifen treatment. One-hundred milligrams of tamoxifen was dissolved in $500 \mu \mathrm{l}$ of $95 \%$ ethanol and diluted with $4.5 \mathrm{ml}$ corn oil to give final concentration of $20 \mathrm{mg} / \mathrm{ml}$. Four-week-old cre-positive mice were given a dose of $3 \mathrm{mg} / 25 \mathrm{~g}$ body weight by oral gavage for 4 or 7 consecutive days. Alternatively, mice were fed tamoxifen-augmented chow (500 $\mathrm{mg} / \mathrm{kg}$, Envigo) for $7 \mathrm{~d}$. In control experiments shown in Figure 1, some cre-negative mice did not receive tamoxifen. For all other experiments, cre-negative littermate mice were also treated with tamoxifen to control for the possible effect of tamoxifen on photoreceptor cell survival (X. Wang et al., 2017).

PCR genotyping. Genomic DNA was isolated from the neural retina. Three PCR primers were used to detect the presence or absence of the neoloxP cassette. Primer 1 sequence (GTTTTATGTAGCAGAGCA GGGAC) is located on intron 19, primer 2 sequence (GAGGAGTAG AAGGTGGCGC) is on neoloxP, and primer 3 sequence (CCACT CCTTAGTACATACCTAAGC) is located on exon 20. A product size of $620 \mathrm{bp}$ from primer pairs $(2+3)$ indicates the presence of neoloxP, and an $802 \mathrm{bp}$ PCR band from primer pairs $(1+3)$ indicates the absence of the neoloxP insert.

Retinal morphology. Mice were rendered unconscious by isoflurane inhalation and immediately followed by cervical dislocation. Retinal sections were prepared as previously described (Concepcion and Chen, 2010; Wang and Chen, 2014). Briefly, before enucleation, eyes were marked for orientation by cauterization on the superior aspect of the cornea. Eyes were placed in $1 / 2$ Karnovsky buffer $(2.5 \%$ glutaraldehyde, $2 \%$ formaldehyde in $0.1 \mathrm{~m}$ cacodylate buffer, $\mathrm{pH} 7.2$ ). The cornea and lens were removed, and the remaining eyecup was further fixed overnight. Fixed eyes were rinsed in $0.1 \mathrm{~m}$ cacodylate buffer, fixed for $1 \mathrm{~h}$ in $1 \% \mathrm{OsO}_{4}$, dehydrated in graded $\mathrm{EtOH}$ and embedded in epoxy resin. Eyecups were hemisected along the superior-inferior axis, and $1 \mu \mathrm{m}$ sections along the central meridian were obtained for light micrographs. For transmission electron microscopy, $50 \mu \mathrm{m}$ sections were obtained, stained with uranyl acetate and lead citrate as described previously (Concepcion and Chen, 2010). Images were taken with a JEOL JEM 2100 microscope.

Immunocytochemistry. Eyecups were prepared as described above in Retinal morphology section, except the tissues were dissected in cold $4 \%$ formaldehyde in PBS and further fixed for $15 \mathrm{~min}$ on ice. For frozen sections, eyecups were rinsed in cold PBS, placed in 30\% sucrose for $1 \mathrm{~h}$, embedded in Tissue-Tek OCT Compound (Sakura Finetek) and flash frozen in liquid $\mathrm{N}_{2}$. Ten micrometer frozen sections were obtained. For retinal flat mounts, four relaxing cuts $\left(0^{\circ}, 90^{\circ}, 180^{\circ}, 270^{\circ}\right)$ were made on the edge of the neural retina and the flattened tissue was immobilized on a piece of nitrocellulose membrane (Whatman, GE Healthcare Life Sciences), photoreceptor side down, as described previously (Anastassov et al., 2019). The tissues were incubated with the following antibodies: rho- 
A
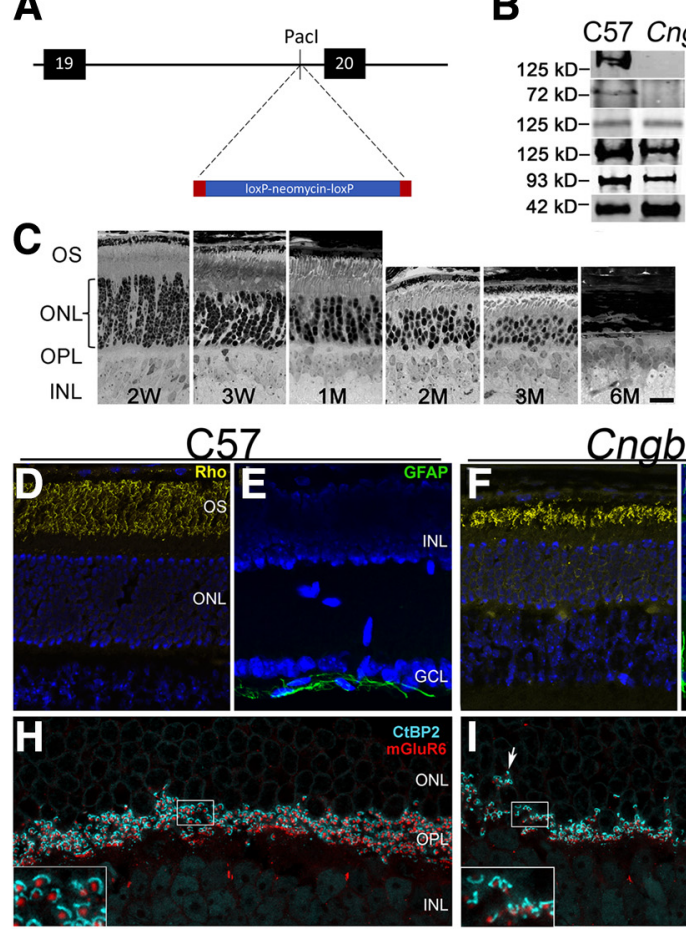

B

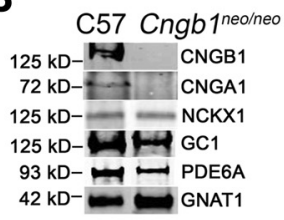

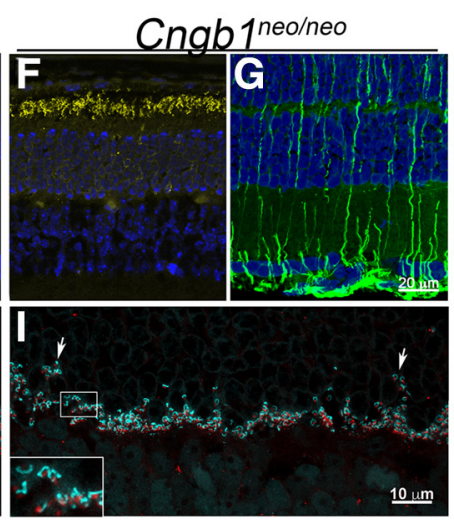
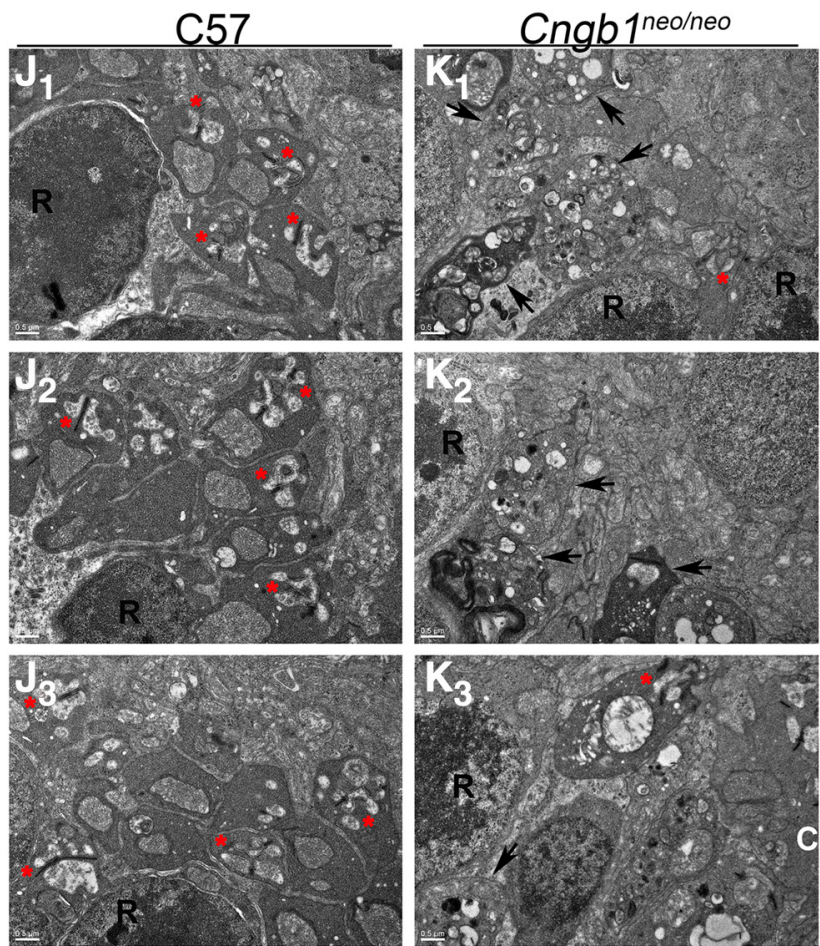

Figure 1. Retinas from Cngb $7^{\text {neo/neo }}$ mice exhibit stereotypic degenerative changes. $\boldsymbol{A}$, The $1.8 \mathrm{~kb}$ neomycin cassette, flanked by loxP sites, was inserted into intron 19 of the $C$ ngb 1 gene. $\boldsymbol{B}$, Western blots of retinal homogenates from control and Cngb $^{\text {neo/neo }}$ mice show that the neomycin insertion blocked expression of CNGB1, and downregulated expression of CNGA1 channel proteins. C, Light micrograph of representative retinal sections prepared from C $\mathrm{ngb} 7^{\text {neo/neo }}$ mice at the indicated ages. Scale bar, $20 \mu \mathrm{m} . \mathbf{D}-\mathbf{I}$, Cryosections from $1 \mathrm{MO}$ C C57 (left) and Cngb $7^{\text {neo/neo }} \mathrm{mice}$ (right) stained for rhodopsin (Rho) and GFAP. Nuclei are stained with DAPI (blue). H, C57 and (I) Cngb $7^{\text {neo/neo }}$ retinal sections stained for synaptic ribbons (CtBP2, blue) of photoreceptors and mGluR6 puncta (red) of bipolar cell dendrites. Representative transmission electron micrographs of $C 57(\boldsymbol{J})$ and $C n g b 7^{\text {neo/neo }}(\boldsymbol{K})$ retinal sections. Rod spherules containing synaptic triads are marked with red asterisk. Dystrophic spherules that contain membranous material and vacuoles (arrows) can be seen in the mutant retina. R: rod nuclei, C: cone pedicle. OS, Outer segment; INL, inner nuclear layer; $\mathrm{GCL}$, ganglion cell layer.

dopsin 1D4 (generously provided by R. Molday, University of British Columbia), GFAP (AB5804, Millipore), CtBP2 (612044, BD Biosciences), PKC (ab32376, Abcam), mGluR6 (generously provided by K. Martemyanov, The Scripps Research Institute), ARR3 (generously provided by C. Craft, University of Southern California). Images were acquired on a Zeiss LSM800 confocal microscope. For quantifications of mGluR6 puncta, images were imported into Fiji (ImageJ2), adjusted to similar threshold and the number and areas of puncta were quantified using the analyze particles function.

Western blots. Each isolated retina was homogenized in $150 \mu \mathrm{l}$ buffer (150 mm NaCl, 50 mm Tris pH 8.0, 0.1\% NP-40, 0.5\% deoxycholic acid, $0.1 \mathrm{~mm}$ PMSF and complete mini protease inhibitor (Roche Applied Sciences), incubated with DNase I (30 U, Roche Applied Sciences) at room temperature for $30 \mathrm{~min}$. An equal amount of retinal homogenate from each sample was electrophoresed on $4-12 \%$ Bis-Tris SDS-PAGE Gel (Invitrogen). Protein was transferred onto nitrocellulose membrane (Whatman, GE Healthcare Life Sciences) and incubated overnight with the following primary antibodies: rabbit anti-PDE polyclonal antibody (PAB-06800, Cytosignal), rabbit anti-ROS-GC1 polyclonal antibody (sc50512, Santa Cruz Biotechnology), mouse Anti- $\mathrm{G}_{\mathrm{t}} \alpha$ antibody (371740, EMD4Biosciences), rabbit polyclonal anti-GCAP1 and GCAP2 antibodies (Hoyo et al., 2014; Wang and Chen, 2014), mouse antiCNGB1 4B1 antibody (Poetsch et al., 2001), mouse anti-CNG $\alpha$ antibody PMc 1D1 (Cook et al., 1989), mouse NCKX1 8H6 antibody (Vinberg et al., 2015), and mouse anti-Actin antibody (MAB1501, Millipore). The membranes were then incubated with fluorescently labeled secondary antibodies (1:10,000; LI-COR biosciences, 926-31081) at room temperature for $1 \mathrm{~h}$ and detected by Odyssey infrared imaging system.

Whole retina and single-cell recordings from rods and bipolar cells. Mice were maintained on a normal $12 \mathrm{~h}$ day/night cycle and were darkadapted overnight $(>12 \mathrm{~h}$ ) before experiments. All further manipulations were performed in total darkness under infrared illumination visualized with infrared image converters (BE Meyers). Following euthanasia, eyes were enucleated, the lens and cornea were removed, and eyecups were stored in darkness at $32^{\circ} \mathrm{C}$ in Ames' media buffered with sodium bicarbonate (Sigma-Aldrich, catalog \#A1420) equilibrated with $5 \% \mathrm{CO}_{2} / 95 \% \mathrm{O}_{2}$.

Trans-retinal electroretinograms (ERGs) were recorded from isolated retinas as described previously (Pahlberg et al., 2017). Retinas were mounted in a specialized recording chamber (Vinberg et al., 2014) and superfused in darkness with $35-37^{\circ} \mathrm{C}$ Ames' media buffered with sodium bicarbonate and equilibrated with $5 \% \mathrm{CO}_{2} / 95 \% \mathrm{O}_{2}, \mathrm{pH} \sim 7.4$. An additional $10 \mathrm{~mm} \mathrm{BaCl}$ was added to the solution facing the inner retina to mitigate Müller cell activity. The trans-retinal potential change to flashes of LED light $\left(\lambda_{\max } \sim 505 \mathrm{~nm}\right.$; Cairn Instruments) was measured using $\mathrm{Ag} / \mathrm{AgCl}$ half-cells connected to a differential amplifier (model DP-311, Warner Instruments). A-waves were separated from b-waves by superfusing retinas with Ames' media containing synaptic blockers $(50 \mu \mathrm{M}$ DL-AP4 and $13 \mathrm{mM} \mathrm{Na}^{+}$Aspartate; Tocris Bioscience and SigmaAldrich), and b-waves were subsequently derived by subtracting a-waves from full ERGs. Recordings were sampled at $1 \mathrm{kHz}$ and low-pass filtered at $30 \mathrm{~Hz}$.

Recordings of the photovoltage from individual rods and rod bipolar cells was made by whole-cell patch-clamp from dark-adapted retinal slices as described previously (Pahlberg et al., 2017). Briefly, a small piece of dark-adapted retina was embedded in low-gelling temperature agar, slices were cut on a vibrating microtome, transferred into a recording chamber, and superfused with Ames' media equilibrated with $5 \% \mathrm{CO}_{2} /$ $95 \% \mathrm{O}_{2}$ while maintained at $35-37^{\circ} \mathrm{C}$. The pipette internal solution consisted of the following (in mM): $125 \mathrm{~K}$-aspartate, $10 \mathrm{KCl}, 10$ HEPES, 5 $\mathrm{N}$-methyl glucamine-HEDTA, $0.5 \mathrm{CaCl}_{2}, 1$ ATP-Mg, 0.2 GTP-Mg; pH was adjusted to 7.2 with $N$-methyl glucamine hydroxide. Light-evoked responses were recorded following the delivery of $10 \mathrm{~ms}$ flashes from a blue LED $\left(\lambda_{\max } \sim 470 \mathrm{~nm}\right.$, full-width half-maximum $\left.\sim 30 \mathrm{~nm}\right)$ whose 
strength varied from producing a just-measurable response, and increased by factors of 2 . Recordings were sampled at $1 \mathrm{kHz}$ and low-pass filtered at $300 \mathrm{~Hz}$.

In vivo $E R G$. Mice were dark-adapted overnight and recordings were performed under dim red light conditions as described previously (Moaven et al., 2013). Series of light flashes ranging from 0.03 mcd to 25 cd were delivered, and responses were recorded using OcuScience HMsERG.

$R G C$ recording, stimulation and analysis. RGCs were recorded from dorsal retina using a large scale, dense hexagonal multielectrode array (MEA) covering $\sim 0.34 \mathrm{~mm}^{2}$ of the retina (519 electrodes with $30 \mu \mathrm{m}$ spacing; Field et al., 2010). The pigmented epithelium remained attached to the retina for these recordings. The retina was perfused with Ames' solution $\left(30-31^{\circ} \mathrm{C}\right)$ bubbled with $95 / 5 \% \mathrm{O}_{2} / \mathrm{CO}_{2}$. Spikes were identified and assigned to specific RGCs on the MEA as previously described (Yu et al., 2017). Dim flashes were delivered at 3 s intervals using a $490 \mathrm{~nm}$ LED. Light intensity was controlled using pulse duration, $2-8 \mathrm{~ms}$, and neutral density filters. Dim flash responses were measured by counting spikes on each trial within a $100 \mathrm{~ms}$ window that was centered on the peak of the peristimulus time histogram.

Experimental design and statistical analyses. Because our initial studies did not show gender-specific differences, the genders were pooled. Student's $t$ test was used to determine statistical significance in morphometric measurements when comparing values between cre-negative and cre-positive mice. RGC response thresholds were measured from three Cngb1 $C a M$ retinas (102-232 cells), five Cngb1 ${ }^{\text {neo/neo }}$ retinas (100-336 cells), and three $C n g b 1^{\text {neo/neo }}$ rescue retinas (53-186 cells). Cumulative threshold histograms were calculated in each tissue and averaged across all retinas within a condition. A two-tailed Kolmogorov-Smirnov goodness-of-fit hypothesis test was used to assess the statistical difference between average cumulative histograms. The fraction of cells for which no response surpassed threshold was also measured in each recorded retina. A two-sample $t$ test was used to evaluate significance between conditions.

\section{Results}

\section{Generation of a novel animal model of genetically reversible rod degeneration}

One challenge to identifying how plasticity among inner retinal neurons impacts functional recovery is the lack of an experimental system that is noninvasive and allows for stringent regulation of the timing and uniformity of rescue. For example, viralmediated (gene therapy) approaches for treating rod dysfunction and death (1) take weeks for expression to occur, (2) they do not infect all targeted cells, (3) they may not drive proper protein expression levels, (4) and the subretinal injections used for viral delivery can damage the retina. A systematic investigation into the consequences of rod degeneration and subsequent rescue of the retinal circuitry requires an experimental system wherein both events occur uniformly in the retina. Toward this goal, a neoloxP cassette was inserted into intron 19 of the Cngbl gene by homologous recombination in mouse embryonic stem cells (Fig. $1 A)$. Mice harboring this insertion were subsequently derived $\left(C n g b 1^{\text {neo/neo }}\right)$. The presence of the cassette disrupted a splice site and prevented CNGB1 expression (Fig. 1B). Expression of CNGA1 was also substantially attenuated (Fig. $1 B$ ), a phenomenon attributed to mistrafficking (Hüttl et al., 2005) and structural stability conferred by association of both subunits. The expression levels of other major phototransduction proteins were minimally perturbed in retinas of 1-month-old (MO) mice (Fig. $1 B$; NCKX1, GC1, PDE6A, and GNAT1). Consistent with previous reports on conventional Cngbl knock-out mice (Hüttl et al., 2005; Zhang et al., 2009), the lack of CNG channel expression led to a progressive thinning of the outer nuclear layer over the course of 6 months (Fig. 1C). At 2 weeks, the outer nuclear layer (ONL) containing primarily rod photoreceptor cell nuclei reached its maximum thickness. This thickness was reduced by $\sim 20 \%$ in $1 \mathrm{MO}$ mice and to $\sim 50 \%$ in $2 \mathrm{MO}$ mice. By $6 \mathrm{MO}$, the ONL was absent. Thus, these mice exhibit slow rod degeneration relative to other commonly used models of rod degenerative diseases, such as $r d 1$ (Farber and Lolley, 1974) and $r d 10$ mice (Chang et al., 2007).

As expected, the absence of the CNGB1 recapitulated the stereotypic sequence of events associated with rod degeneration (Marc and Jones, 2003; Puthussery and Taylor, 2010; Soto and Kerschensteiner, 2015). For example, rhodopsin mislocalization and activation of Müller glia were observed in 4-week-old $C n g b 1^{\text {neo/neo }}$ mice (Fig. 1, compare F, G, with control retina, $D, E)$. Further, their outer segments were shortened (see also below), and the membranous disks become disorganized (Fig. 3I; Gilliam et al., 2012).

We also observed in $C n g b 1^{\text {neo/neo }}$ mice that synaptic contacts between rods and rod bipolar cells were structurally abnormal. Immunohistochemistry using a marker for the presynaptic ribbon protein CtBP2 (ribeye) and the postsynaptic glutamate receptor, mGluR6, revealed clear differences between $\mathrm{Cngb1}^{\text {neo/neo }}$ and control retinas. In control retinas, these structures were closely apposed, and both were contained within a well defined outer plexiform layer (OPL; Fig. 1H,). However, in $\mathrm{Cngbl}^{\text {neo/neo }}$ retinas these structures were less aligned within the laminar boundary of the outer plexiform layer and some were situated deep into the photoreceptor nuclear layer (ONL; Fig. 1I, arrows). The ultrastructure of rod synapses was further evaluated by transmission electron microscopy (TEM). Representative images of retinal sections from 1 MO C57 mice show numerous triads consisting of the synaptic ribbon, and horizontal and bipolar cell dendrites within rod spherules (Fig. $1 J$, red asterisks). Diads were also observed when one of these elements was out of the plane of the section. Triads were less numerous in rod spherules of agematched $\mathrm{Cngbl}^{\text {neo/neo }}$ mice; instead, many dysmorphic membranous and vesicular structures were present (Fig. $1 K$, arrows). Importantly, no such structures were observed in C57 TEM images. Quantification of triads, diads, and dysmorphic structures are shown in Figure $5 E$.

\section{Lack of CNGB1 expression attenuated rod photoresponses and rod bipolar cell light responses}

Previous work has indicated that lack of CNGB1 expression compromises rod vision (Biel and Michalakis, 2007). To verify compromised rod function in $C n g b 1^{\text {neo/neo }}$ mice, we performed ex vivo whole-retina ERGs under scotopic conditions. The ERG reflects the averaged activity across all retinal neurons (Granit, 1933). ERGs from C57 retinas exhibited a well characterized biphasic response (Fig. 2A; Saszik et al., 2002) with the initial negativevoltage deflection (a-wave) indicative of the rod hyperpolarization to the flash stimulus, and the subsequent positive-voltage rebound indicative of predominantly the rod bipolar cell depolarization (b-wave). We isolated a-waves during the superfusion of synaptic blockers and rod b-waves by subtracting a-waves from the full ERG. Recordings were also performed on control Cngb1 $\Delta C a M$ mice in which the calmodulin binding site was removed (Chen et al., 2010). No differences were observed between Cngb1 $\mathrm{CaM}$ and C57 retinas (data not shown).

Although ERGs from $1 \mathrm{MO} C n g b 1^{\text {neo/neo }}$ retinas exhibit some variability, all exhibit reduced function. As shown in Figure 2, 1 MO Cngb1 $1^{\text {neo/neo }}$ retinas displayed reduced sensitivity a-waves and b-waves. Light responses were not fully eliminated in these rods; this is likely because of residual activation of homomeric channels composed of CNGA1 (see Discussion). B-waves, how- 

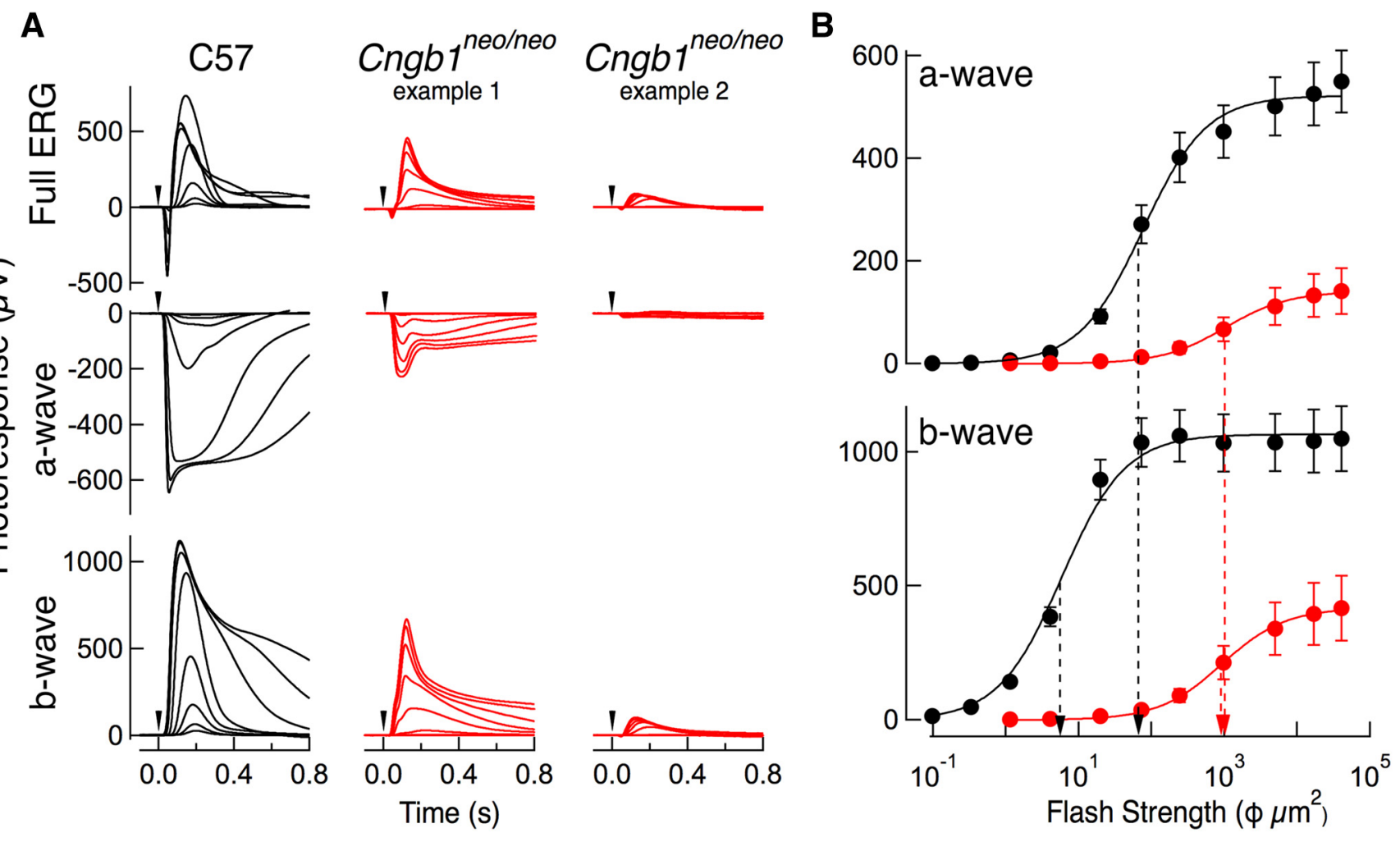

Figure 2. Characterization of rod and rod bipolar function by ex vivo ERGs. Rod-driven a-waves were isolated with pharmacological inhibitors of synaptic transmission (see Materials and Methods), and rod bipolar-dominated b-waves were subsequently derived by subtracting the a-wave from the full ERG. $A$, Example recordings from a typical $C 57$ retina, and two $1 \mathrm{M} 0$ C $n g b{ }^{\text {neo/neo }}$ retinas with a-waves and b-waves separated. Flash strengths in all families ranged between 0.10 and 40,000 photons $\mu m^{2}{ }^{2}$, with nonresponding and supersaturating responses omitted for clarity. $\boldsymbol{B}$, Response-intensity relationships for isolated a-waves and derived $b$-waves. Points plotted as mean \pm SEM. A-wave and $b$-wave data were fit by Hill Equations with the exponent fixed at 1 . C 57 a-wave fits yielded an $R_{\max }$ of $520 \mu \mathrm{V}$ and $I_{1 / 2}$ of 75 photons $\mu \mathrm{m}^{2}$, with $C$ ngb $1^{\text {neo/neo }}$ a-wave fits yielding an $R_{\max }$ of $140 \mu \mathrm{V}$ and $\mathrm{I}_{1 / 2}$ of $1030 \mathrm{photons} \cdot \mu \mathrm{m}{ }^{2}$. C57 $\mathrm{b}$-waves fits yielded an $R_{\text {max }}$ of 1070 $\mu \mathrm{V}$ and $I_{1 / 2}$ of 5.8 photons $\mu \mathrm{m}^{2}$, with $C$ ngb $1^{\text {neo/neo }} \mathrm{b}$-wave fits yielding an $R_{\max }$ of $420 \mu \mathrm{V}$ and $I_{1 / 2}$ of 930 photons $\mu \mathrm{m}^{2}$. Dashed lines are included from the $I_{1 / 2}$ value of each fit to the light intensity axis to allow comparison of the larger relative desensitization of $b$-waves compared with a-waves.

ever, ranged in size between somewhat desensitized to completely absent. Response-intensity relationships (Fig. 2B) demonstrate a rightward shift of both a-waves and b-waves in $\mathrm{Cngbl}^{\text {neo/neo }}$ retinas, indicating an $\sim 14$-fold desensitization of the a-wave but $\sim 160$-fold desensitization of the b-wave. The larger relative desensitization of the b-wave is indicative of a synaptic deficit in addition to the deficit in phototransduction. This observation complements the abnormal synaptic structures observed between rods and rod bipolar cells via light and electron microscopy. Together, these results indicate that synaptic transmission between rods and rod bipolar cells is severely dysfunctional in Cngb1 $1^{\text {neo/neo }}$ mice. Thus, we sought to determine the extent to which normal synaptic structures and transmission between rods and rod bipolar cells could be recovered by the rescue of CNGB1 expression in mature retinas.

\section{Cre-mediated excision of the NeoLoxP cassette leads to normal CNGB1 expression}

To activate CNGB1 expression in the $C n g b 1^{\text {neo/neo }}$ retina, we used the CAGGCre-ER transgene (Hayashi and McMahon, 2002) to enable tamoxifen-dependent, cre-mediated excision of the $\mathrm{Ne}$ oloxP cassette. We previously demonstrated that mice derived from germline excision of this cassette exhibit normal retinal morphology with a uniform and normal expression level of CNGB1 (Chen et al., 2010). The homologous recombination strategy that introduced the NeoloxP cassette also removed a stretch of 14 aa that encompassed the calmodulin binding domain on CNGB1 (Grunwald et al., 1998). Importantly, rods that expressed CNGB1 $\Delta$ CaM exhibited normal light responses as mentioned (Chen et al., 2010). We hypothesize that using the CAGGCre-ER transgene would provide temporal control over expression of the functional CNG channel. To determine the efficacy of cre-mediated excision of the neoloxP cassette, 4-weekold cre-positive and cre-negative $C n g b 1^{\text {neo/neo }}$ littermate mice were divided into two groups. One group was given tamoxifen for 4 consecutive days by oral gavage, and the other group did not receive drug treatment.

A PCR strategy was designed to detect the extent of neoloxP excision in genomic DNA extracted from isolated retinas: the primer pair $(2+3)$ detects the presence of the neoloxP insert, whereas primer pair $(1+3)$ gives rise to a diagnostic band when the large neoloxP insert is excised (Fig. $3 A$ ). After 4 consecutive days of tamoxifen treatment, both sets of primers produced positive bands. This result indicates a mixed population of cells at this stage, some of which have undergone excision while others have not. However, when tamoxifen treatment was given for 7 consecutive days a positive signal was detected only by primers $(1+3)$. This result indicates that following a $7 \mathrm{~d}$ tamoxifen treatment, most, if not all cells have undergone neoloxP excision (Fig. 3A, bottom). Thus, a $7 \mathrm{~d}$ treatment was used for further structural and functional studies.

To assess the level of protein expression at 6 or 8 weeks (corresponding to 1 or 3 weeks after drug treatment), Western blots were prepared from whole retinal homogenates from both cohorts (Fig. 3B). Expression of CNGB1 protein was observed only in tamoxifen-treated, cre-positive mice. No expression was ob- 
A
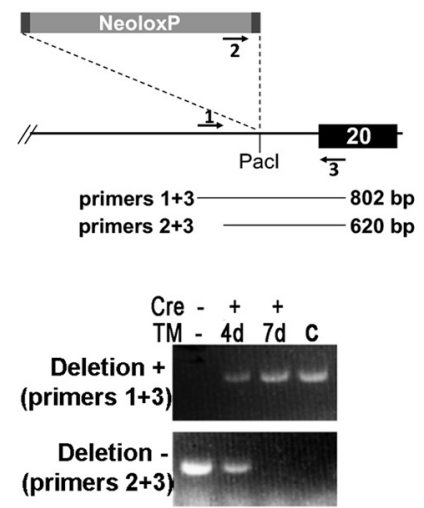

B

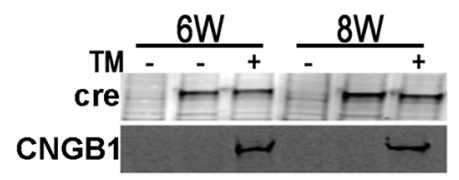

C

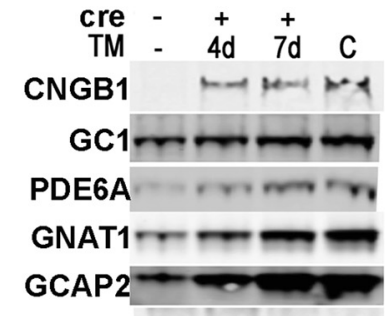

Actin

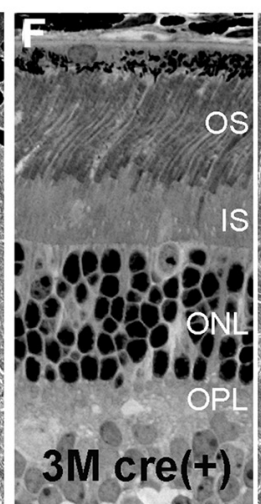

I
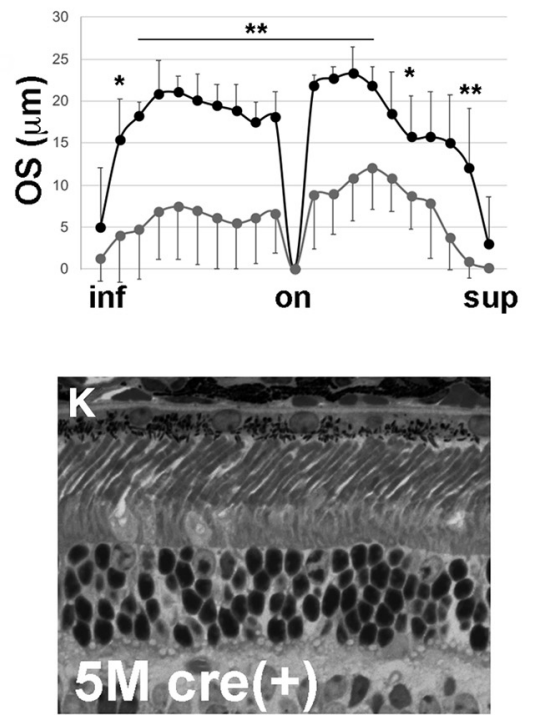

$\mathbf{L}$
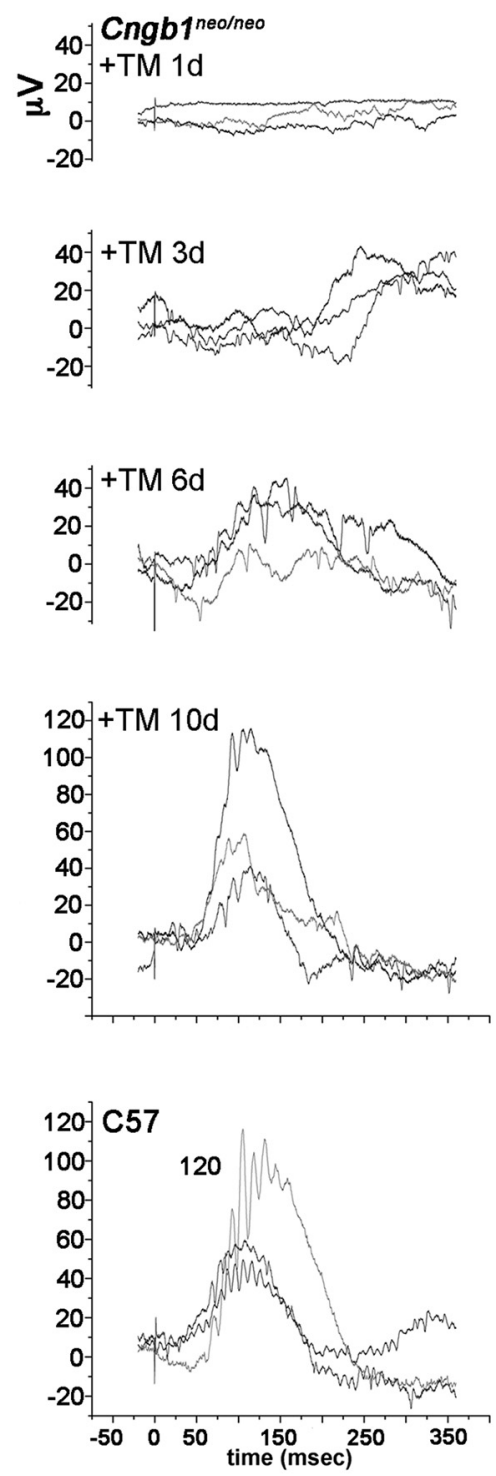

M

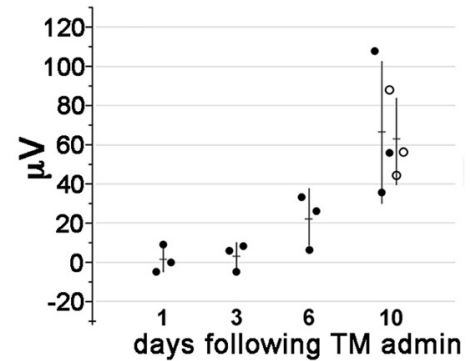

Figure 3. Excision of the floxed neomycin cassette restores CNG channel expression and rescues rod cell death. $\boldsymbol{A}, \mathrm{PCR}$ primers 1,2 , and 3 were designed to detect the presence or absence of the neoloxP cassette. Littermate mice were treated with tamoxifen (TM) for the indicated number of days starting at 4 weeks and retinal DNA was extracted from mice at 8 weeks. Control retinal DNA " $c$ " is from a germline-floxed mouse wherein the neoloxP cassette has been removed in all tissues (Cngb1 $\triangle$ CaM ). B. Western blots of retinal homogenates from cre-negative and cre-positive littermate mice of the indicated ages ( 6 weeks, 8 weeks) that were treated with TM or vehicle (corn oil) beginning at 4 weeks old for 4 consecutive days. $C$, Western blot of retinal homogenate prepared from the contralateral eye from mice used in $\boldsymbol{A}$. Representative retinal morphology and outer segment structure of $3 \mathrm{M} 0$ cre-negative $(\boldsymbol{D}, \boldsymbol{E})$ or cre-positive littermates $(\boldsymbol{F}, \boldsymbol{G})$ mice treated with tamoxifen for 7 consecutive days beginning at 4 weeks. Quantification of outer nuclear layer thickness $(\boldsymbol{H})$ and outer segment length $(\boldsymbol{I})$ across the central meridian of the retina at 20 positions along the inferior-superior axis (mean $\pm S D, n=4$ for cre-positive; $n=5$ for cre-negative mice). Positions showing significant difference by Student's $s$ test are marked by ${ }^{*} p<0.05$ and ${ }^{* *} p<$ 0.01. Retinal morphology from $5 \mathrm{MO}$ cre-negative $(\boldsymbol{J})$ and cre-positive $(\boldsymbol{K})$ littermates treated with tamoxifen for 4 consecutive days starting at P28. $L$, In vivo ERG from tamoxifen-fed $\left(n g b 1^{\text {neo/neo }}\right.$ mice ( $n=3$, individual mice are color-coded light gray, dark gray, and black) recorded after the indicated days of tamoxifen treatment. Traces shown are from individual mice responding to $1 \mathrm{mcd}$ light flash. $M$, Summary of b-wave values (mean \pm SD) from L. Filled circles represent data from tamoxifen-fed $C n g b 1^{\text {neo/neo }}$ mice and open circles represent values from age-matched C57 controls. 
A

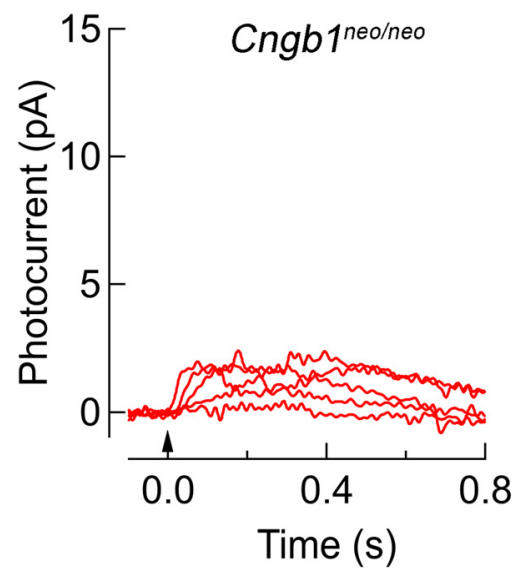

B

\section{Cngb1 rescued}

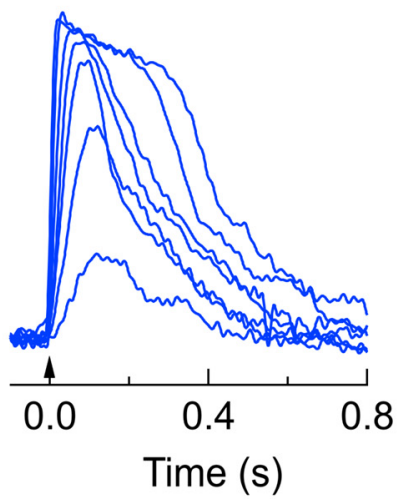

C

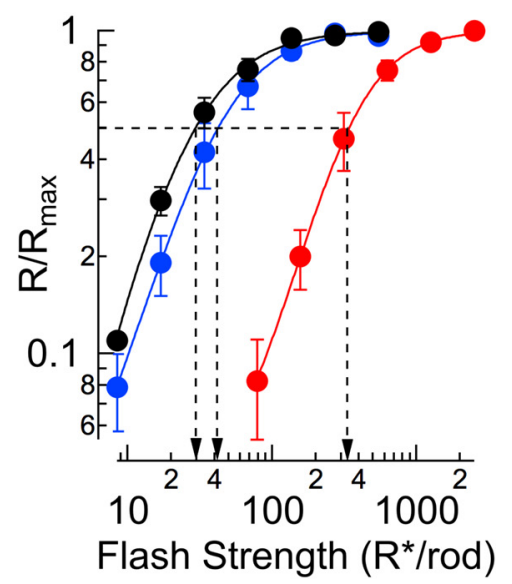

Figure 4. Light sensitivity is improved following expression of CNGB1. $\boldsymbol{A}$, Single cell recordings show small, desensitized response families in Cngb $^{\text {neo/neo }}$ mice likely reflecting residual CNG channels composed of CNGA1 monomers. Flashes generated 79, 160, 310, 630, and $1300 \mathrm{Rh} *$ rod. $\boldsymbol{B}$, Following tamoxifen treatment, rod responses showed amplitudes and sensitivity resembling those of C57; flash strengths were 9, 17, 34, 68, 140, 270, and $540 \mathrm{Rh}$ /rod. C, Response-intensity relationships from single-cell recordings display $\sim 10$-fold reduction in sensitivity between WT (black dots) and Cngb $1^{\text {neo/neo }}$ [red dots; $/ 1 / 2$ values were $27 \pm 4(n=5)$ and $360 \pm 8(n=9)$, respectively]. This sensitivity shift is nearly restored following reintroduction of the CNGB1 [blue dots; $l 1 / 2=43 \pm 3(n=10)]$.

served in cre-positive mice without drug treatment, indicating a lack of basal recombinase activity. We next examined how excision of the neoloxP insert affected the expression of CNGB1 and other major phototransduction proteins. We found that following neoloxP excision, there was a striking increase in CNGB1 expression (Fig. 3C). There was also an increase in the detected levels of other phototransduction proteins GC1, PDE6A, GNAT1, and GCAP2 at 8 weeks (Fig. 3C). To determine whether this is because of rod rescue, cre-negative and cre-positive $C n g b 1^{\text {neo/neo }}$ littermate mice were administered tamoxifen for 7 consecutive days beginning at 4 weeks, and retinal sections were prepared from $3 \mathrm{MO}$ mice. In the absence of rescue, cre-negative sibling mice show a reduction in outer nuclear layer thickness and disrupted outer segment structures (Fig. $3 D, E$ ), whereas the cre-positive mice showed more layers of photoreceptor cells, and the rod outer segment were longer and contained organized disks. Importantly, disruption of outer segment structure in the Cngb1 knock-out rods is evident by postnatal day (P)20 (data not shown; but see Zhang et al., 2009; Gilliam et al., 2012). Therefore, this result reveals an inherent ability of the outer segment renewal process to form organized discs upon gene rescue; the outer segment renewal process takes $10 \mathrm{~d}$ in the mouse retina as the newly formed discs at the base reaches the tip of the outer segment (LaVail, 1973). Quantification of the outer nuclear layer thickness at 20 different positions along the central meridian of the retina showed a significant difference at the inferior-central region (Fig. $3 H$ ). Difference in the outer segment length was more striking, and significant differences were seen in most regions of the retina (Fig. 3I). Expression of CNGB1 exhibited a long term rescuing effect on rod survival (Fig. $3 \mathrm{~J}, \mathrm{~K}$; tamoxifen was administered for 4 consecutive days starting at P28), consistent with a previous report on AAV-mediated Cngbl gene replacement therapy (Koch et al., 2012). The time course of functional recovery following $7 \mathrm{~d}$ tamoxifen treatment was measured by in vivo ERG (Fig. $3 L, M$ ) where the dimmest flash $(1 \mathrm{mcd}$ ) reliably recorded from C57 mice are used for visual threshold. No responses were detected until $6 \mathrm{~d}$ after initiation of drug treatment, and after $10 \mathrm{~d}$ the responses from cre-positive mice appeared similar to that of C57 mice (Fig. 3L). Quantification of b-wave amplitudes as a function of time is shown in Figure $3 M$. In sum, these data show that the $C n g b 1^{\text {neo/neo }}$ mice allowed us to regulate the expression of CNGB1 from the endogenous locus in a temporally-controlled manner. Further, this excision is nearly complete with a $7 \mathrm{~d}$ tamoxifen treatment and that upon expression of CNGB1, the rods elaborate long outer segments and are stably rescued from cell death.

We measured the responsiveness of rod photoreceptors following drug treatment in patch-clamp recordings from individual rods in retinal slices. In voltage-clamp $\left(V_{\mathrm{m}}=-40 \mathrm{mV}\right)$, rods from $1 \mathrm{MO} C n g b 1^{\text {пеo/neo }}$ mice displayed diminished response amplitudes ( $\sim 6$-fold) and a $\sim 10$-fold reduction in light sensitivity (Fig. $4 A$ ), a result consistent with the diminished a-wave in ex vivo ERG recordings (Fig. $2 B$ ). In current-clamp ( $i=0), C n g b 1^{\text {neo/neo }}$ rods exhibit a resting membrane potential that was $\sim 10 \mathrm{mV}$ hyperpolarized compared with WT rods $[-47 \pm 1.3 \mathrm{mV}(5)$ vs $-37 \pm 2.3 \mathrm{mV}(6)$, mean $\pm \mathrm{SEM}]$. These results are consistent with reduced CNG channel expression (see Discussion) and indicate reduced glutamate release in darkness. However, rods from tamoxifen-treated $C n g b 1^{\text {neo/neo }}$ mice displayed responses with characteristics very similar to C57 mice (Fig. 4B), consistent with near-normal function and rescue of the photoreceptor layer (Fig. 3).

\section{Expression of CNGB1 induces normal synaptic structures between rods and rod bipolar cells}

Given that tamoxifen administration in $C n g b 1^{\text {neo/neo }}$ mice rescued rods from death (Fig. $3 D-K$ ) and rescued normal rod light responses (Fig. 4), we next examined the synaptic contacts between rods and rod bipolar cells to determine how rod rescue impacts these structures. Tamoxifen treatment was initiated at 4 weeks for 7 consecutive days, and retinal structure was examined at 3 MO. Comparisons were made between 1 MO C57 and $\mathrm{Cngbl}^{\text {neo/neo }}$ mice and $3 \mathrm{MO}$ tamoxifen-treated mice to examine the effect of rod rescue that was initiated at $1 \mathrm{MO}$. Synaptic structures were labeled in retinal flat mounts stained for the presynaptic ribbon synapse protein ( $\mathrm{CtBP} 2$, blue) and postsynaptic mGluR6 (orange; Fig. $5 A, B, C$ ). To distinguish between rod and cone synapses, cone pedicles were further labeled with the conearrestin antibody (ARR3, green). Rod bipolar cell morphology, visualized by PKC $\alpha$ staining, and the mGluR6 puncta that deco- 

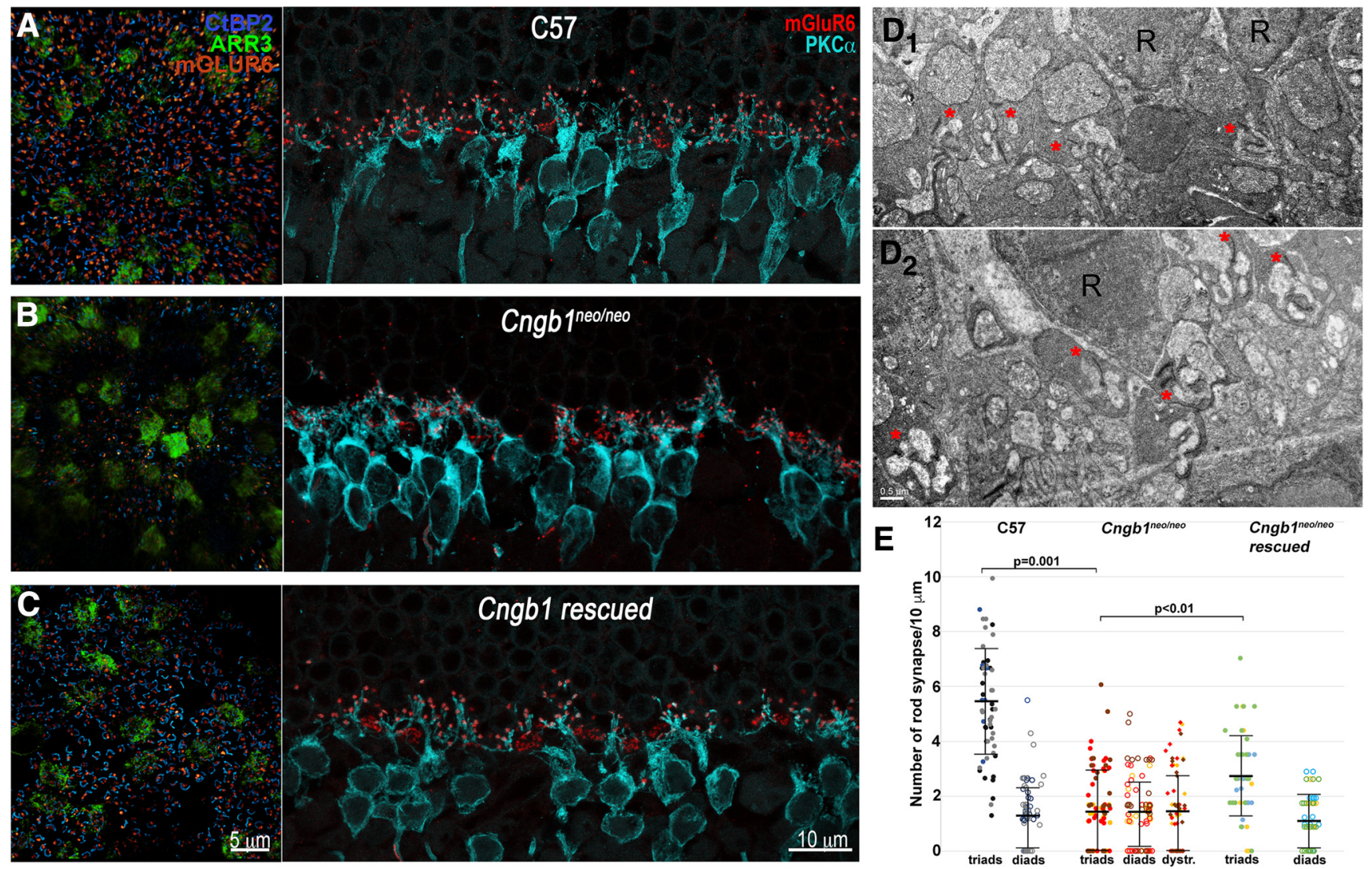

Figure 5. Expression of CNGB1 reverses presynaptic and postsynaptic retinal remodeling in $C$ ng $b 7^{\text {neo/neo }}$ retina. Shown are representative images from $\mathrm{N}=$ seven independent experiments. $\boldsymbol{A}-\boldsymbol{C}$, Left, Retinal flat mounts from $1 \mathrm{MO}$ C $57,1 \mathrm{MO}$ Cngb $7^{\text {neo/neo }}$, and $3 \mathrm{MO}$ rescued Cngb1 mice treated with tamoxifen for 7 consecutive days beginning at 4 weeks of age, respectively. The flat mounts were stained with the presynaptic ribbon marker, CtBP2 (blue), and postsynaptic marker mGluR6 (orange). Cone pedicles were visualized using cone arrestin, ARR3 (green). Right, Retinal cross sections from mice of the same genotype as the flat mounts. The retinal sections were stained with antibodies to mGluR6 (red) and the rod bipolar cell marker, PKC $\alpha$ (teal). $\boldsymbol{D}$, Representative TEM of Cngb1 rescued mice. Rod spherules containing synaptic elements are marked by red asterisk. $\boldsymbol{E}$, Quantification of synaptic triads and diads as well as dystrophic spherules from C57, Cngb ${ }^{\text {neo/neo }}$, and (ngb1 rescued mice ( $n=3$ for each group). Each independent sample are marked by a different color, and each point represents the number of synaptic structures counted in one TEM image field, normalized to $10 \mu \mathrm{m}$ distance of the outer plexiform layer. No dystrophic structures were observed in images from C57 retinas. Values are mean \pm SD. Groups are compared first by one-way ANOVA followed by Tukey HSD.

rate their dendritic tips are shown in retinal cross sections on the right.

Control retinas (C57), exhibited a close juxtaposition between the rod's single ribbon and the mGluR6 puncta on the dendritic tips of rod bipolar cells (Figs. 5A, 1G). However, in Cngb $1^{\text {neo/neo }}$ retinas from $1 \mathrm{MO}$ mice, both the number of synaptic ribbons and mGluR6 puncta appear reduced in the retinal flat mount (Fig. 5B, left). This reduction is likely due, in part, to mislocalization of some of these structures into the outer nuclear layer (Fig. 1I). Rod bipolar cell dendrites were also unevenly distributed in $C n g b 1^{\text {neo/neo }}$ retinas, and the size of the mGluR6 puncta appeared smaller (Fig. 5B). In contrast, retinas from the tamoxifen-treated, cre-positive littermates exhibited robust staining of synaptic ribbons along with their associated mGluR6 puncta, and rod bipolar cell dendrites were evenly extended and the mGluR6 puncta appeared more uniform in shape (Fig. $5 C$ ). The rod spherule of the rescued mice were further examined by TEM, where triads were reliably observed (Fig. 5D). Interestingly, many of these appear larger and contain more extensive cellular processes compared with triads in C57 spherules (Fig. 1J). Notably, similar to C57 controls, no dysmorphic synaptic structures were observed in sections from tamoxifen-treated mice. Quantification of synaptic structures in TEM sections from 1 MO C57, Cngb $1^{\text {neo/neo }}$ and rescued mice is shown in Figure $5 E$ (mean $\pm \mathrm{SD}, N=3$ for each group). A significant reduction in triads was observed in Cngb $1^{\text {neo/neo }}$ retinal sections compared with that from C57 mice, and these structures increased upon tamoxifen treatment. The overall decrease in the number of synapses is consistent with the degree of rod loss before tamoxifen rescue. These results indicate that inducing expression of CNGB1 in mature retina causes a recovery of synaptic structures between rods and rod bipolar cells.

\section{Rescue of CNGB1 expression in mature retina recovers rod bipolar light responses}

The results above indicate a structural recovery of synapses following expression of CNGB1. In addition to this structural recovery, ex vivo whole-retina ERGs revealed a recovery and stabilization of the rod bipolar cell-driven b-wave (Fig. 6A). Because of variations in the size of the a-wave and b-wave in $C n g b 1^{\text {neo/neo }}$ mice, in Figure $6 \mathrm{~A}$ (right) we show the normalized b-wave response-intensity relationships from Figure $2 B$ along with the recovery. These data show that the sensitivity of the b-wave recovers following tamoxifen treatment to values similar to $\mathrm{C} 57$ retinas. Thus, structural and functional measures broadly indicate recovery of synaptic function between rods and rod bipolar cells. To examine further synaptic function before and following rod rescue, we performed patch-clamp recordings from 

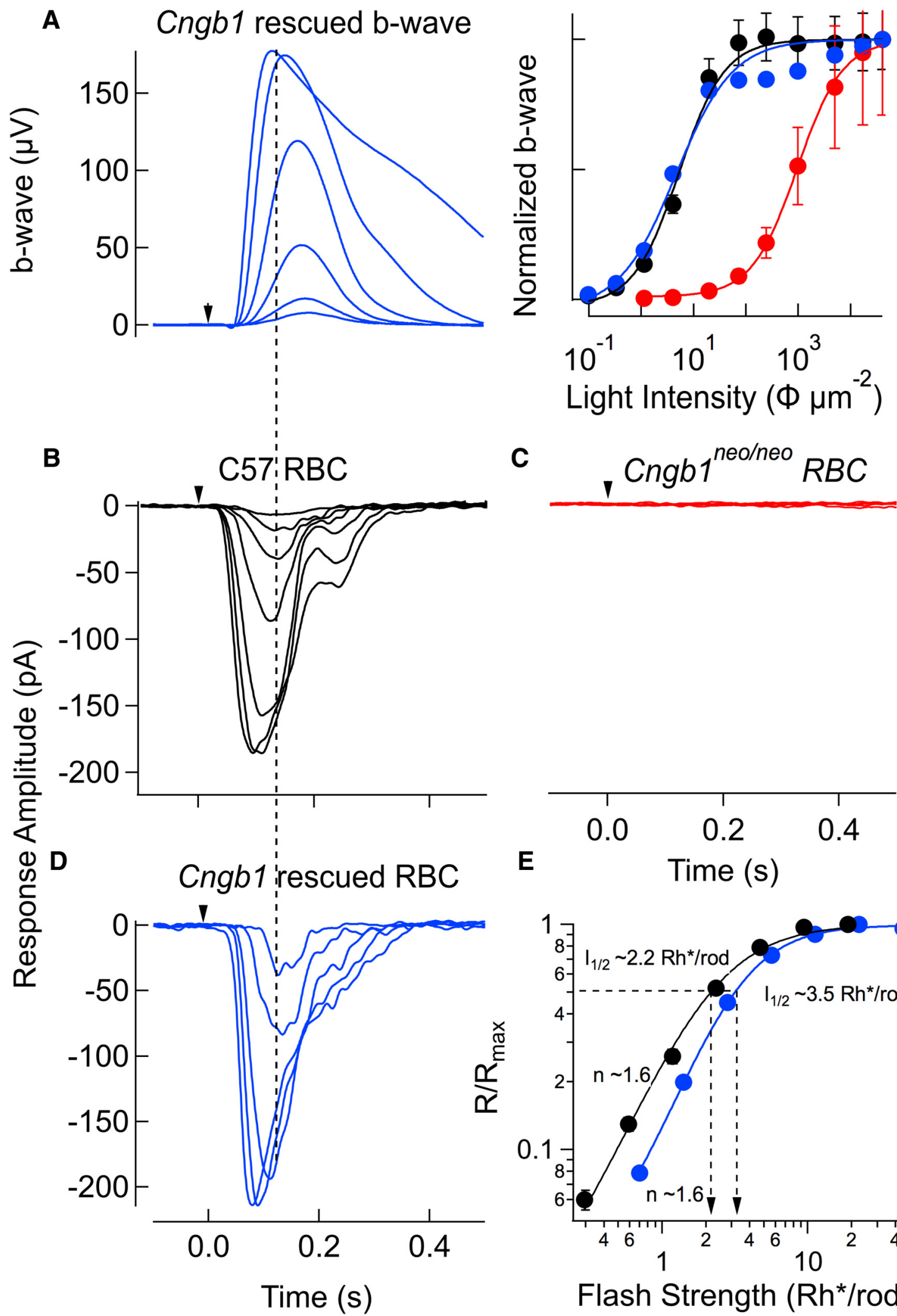

C
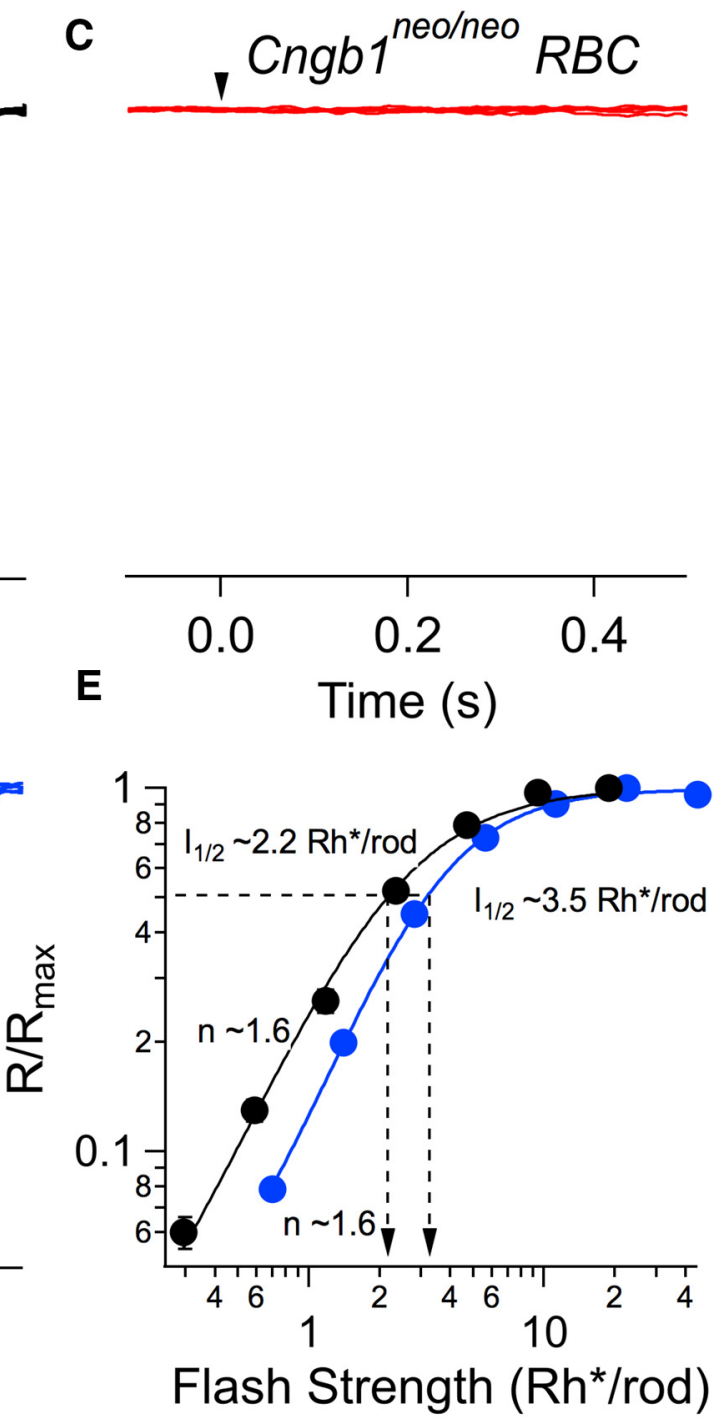

Figure 6. Physiological responses from rod bipolar cells in retinal slices. $A$, Ex vivo ERG $b$-wave responses from 3 to $6 \mathrm{MO} C \mathrm{Cngb} 7^{\text {neo/neo }} \mathrm{Cre}+$ mice after tamoxifen treatments. Flashes delivered $0.33,1.1,4.0,20,72$, and 240 photons $\mu \mathrm{m}^{-2}$. Please compare with Figure $2 A$. Voltage-clamp rod bipolar cell recordings $\left(V_{\mathrm{m}}=-60 \mathrm{mV}\right)$ from the following mice: (B) $C 57 \mathrm{rod}$ bipolar cells $(2-3$ MO); (C) Cngb $7^{\text {neo/neo }}$ rod bipolar cells (1 M0); (D) Cngb1 tamoxifen-treated (3 MO). Flashes generated 2, 4, 8, 16,31, 62, and $130 \mathrm{Rh}^{*} / \mathrm{rod}$ for C57 rod bipolar cells, and 280, 560, 1100, and 2200

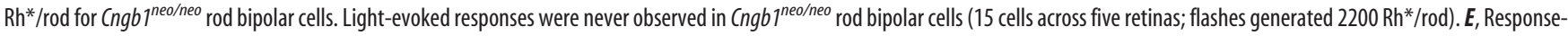
intensity relationships from mean data show that this relationship is shifted to higher flash strengths in rescued mice, reflecting some rod loss. The Hill exponent of rod bipolar cells were similar to normal following rod recovery (Hill exponent $=1.6 \pm 0.05 ; n=12$ ), in support of a restoration of the normal rod-to-rod bipolar cell synaptic structure and the dark rate of glutamate release. 

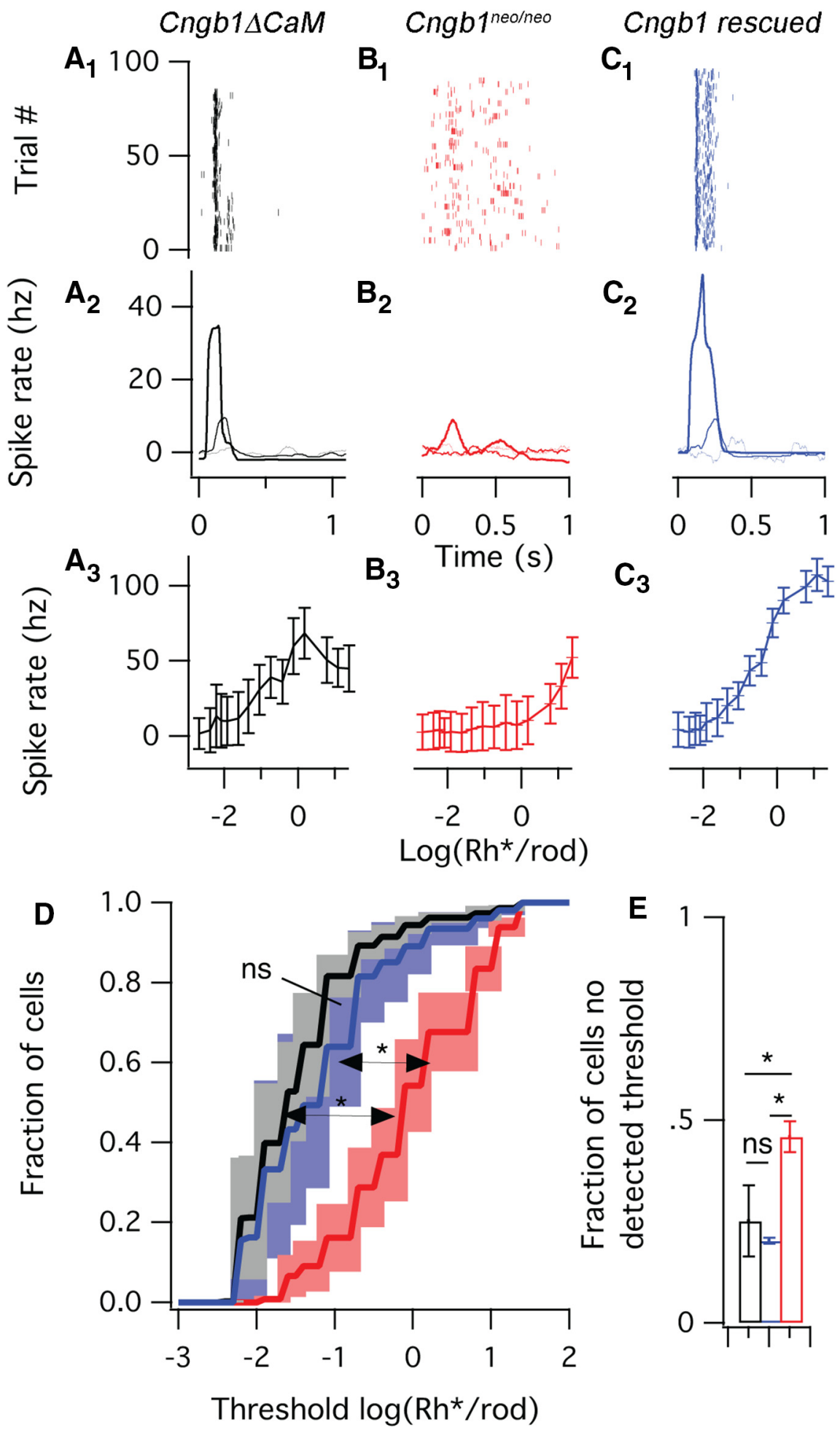

Figure 7. Dim flash responses from RGCs in whole-mount retina show recovery from early rod rescue. $A_{1}-C_{1}$, Spike times of $80-100$ trials of three example cells to a single dim flash $\left(0.75 \mathrm{Rh}^{*} / \mathrm{rod}\right) . A_{2}-C_{2}$, PSTHs for three increasingly bright dim flashes $(0.002,0.02,0.75, \mathrm{Rh} * / \mathrm{rod}) . A_{3}-C_{3}$, The mean spike rate $\pm S D$, measured on each trial in a $100 \mathrm{~ms}$ window around the peak of the PSTH. Dim flash thresholds were estimated from these curves for 1954 cells. The average cumulative distribution function show higher thresholds responses in $C n g b 7^{\text {neo/neo }}$ mice RGCs than Cngb1 $\Delta$ CaM and tamoxifen-treated Cngb $7^{\text {neo/neo }}$ mice RGCs (D). The shaded regions illustrate standard error of the mean (SEM) across 3- 4 experimental preparations. Additionally, flash thresholds could not be identified in a larger portion of $\mathrm{RGCs}$ from $\left(n g b 7^{\text {neo/neo }}\right.$ mice $(\boldsymbol{E})$. $^{*} p<0.01$, ns, not significant.

rod bipolar cells in retinal slices. In untreated $C n g b 1^{\text {neo/neo }}$ mice there was a complete absence of functional transmission of between rods and rod bipolar cells (Fig. 6C); $1 \mathrm{MO} C n g b 1^{\text {neo/neo }}$ rod bipolar cells never yielded light-evoked responses $(n=15$ from 5 retinas; see also Discussion). However, in $\mathrm{Cngb1}^{\text {neo/neo }}$ mice administered tamoxifen for $7 \mathrm{~d}$ at 4 weeks of age and recorded at $3 \mathrm{MO}$, rod bipolar cells exhibited robust light-evoked responses similar to control animals (Fig. 6D). The extent of functional recovery in rod bipolar cells was characterized in plots of the response amplitude versus the flash strength. These intensity-response relationships were fit with a Hill curve and compared quantitatively to control responses. The halfmaximal flash strength $\left(I_{1 / 2}\right)$ increased by $\sim$ twofold in rescued animals (Fig. $6 E$ ), consistent with some rod loss (see Discussion). However, other features of the rod bipolar light response that are critical for function near visual threshold had recovered to near control values. For example, the Hill exponent for the fit of the response-intensity relationship matched that in control, indicating a similar nonlinear relationship between the flash strength and the response amplitude. The extent of nonlinearity reflects the rate of glutamate release from rod synapses (Sampath and Rieke, 2004). In addition, the time course of rod bipolar cell responses was similar in rescued animals (Fig. 6A, C,E, dashed line), further indicating the anatomical and physiological recovery of synaptic transmission in tamoxifen-treated animals. These results indicate that rescuing rod function in the mature mouse retina produces a cascade of structural and functional recovery in synaptic transmission between rods and rod bipolar cells, and thus the primary rod pathway (Dacheux and Raviola, 1986).

\section{Rescuing rods recovers absolute sensitivity of retinal output}

RGCs provide the sole output from the retina and can integrate input from thousands of rods, making them the most light-sensitive cells in the retina (Chichilnisky and Rieke, 2005; Field and Sampath, 2017). RGC sensitivity relies on functioning photoreceptors and highly tuned synaptic connections via the primary rod pathway (Field and Rieke, 2002; Sampath and Rieke, 2004). To understand how rescuing rod function in the $1 \mathrm{MO}$ $C n g b 1^{\text {neo/neo }}$ retina impacts RGC sensitivity, we used a large-scale MEA to record spikes from hundreds of RGCs. We tested the sensitivity of the RGCs by stimulating the retina with brief, dim flashes (0.001-10 $\left.\mathrm{Rh}^{\star} / \mathrm{rod}\right)$ and compared RGC responses in $3 \mathrm{MO}$ control Cngb1 $\triangle \mathrm{CaM}, \mathrm{Cngbl}^{\text {neo/neo }}$, and 4-5 MO Cngb1 tamoxifen rescued mice. Flashes producing $<1$ isomerization per rod faithfully produced spike rate modulations in many RGCs from control mice (Fig. $7 A$ shows an example 
cell). The same flash intensities did not reliably modulate the

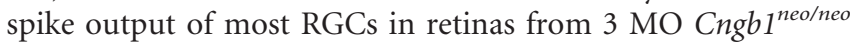
mice (Fig. $7 B$ shows an example cell). Indeed, most RGCs from $C n g b 1^{\text {пеo/neo }}$ mice did not show reliable responses until flash intensities exceeded $1 \mathrm{Rh}^{\star} / \operatorname{rod}$ (Fig. $7 B_{3}$ ). However, similar to the control retinas, RGC responses were often evident at low flash intensities in 4-5 MO Cngb1 rescued mice (Fig. 7C shows an example cell). These example cells suggest that rod and circuit functionality are broadly and stably rescued in some RGCs for Cngb1 rescued mice.

To measure the extent that sensitivity across the RGC population recovered in $C n g b 1$ rescued mice, we quantified the response-threshold for all RGCs $(N=1954)$ in MEA recordings from 11 mice ( 3 control Cngb1 $\Delta C a M$ mice, $3 C n g b 1^{\text {neo/neo }}$ mice, 5 tamoxifen-treated $C n g b 1$ mice). RGC response thresholds were quantified as the lowest flash intensity needed to drive the average spike rate change $2 \mathrm{SD}$ above baseline (Fig. $7 A_{3}, B_{3}, C_{3}$; see Materials and Methods). Average RGC response threshold distributions were similar between control and $C n g b 1$ rescued mice, but were significantly higher in untreated $C n g b 1^{\text {neo/neo }}$ mice (Fig. $7 D$; KS test, $p<0.05$ ). Additionally, the fraction of RGCs for which no-threshold response could be measured was similar between control and $C n g b 1$ rescued mice but significantly higher in untreated $C n g b 1^{\text {neo/neo }}$ mice (Fig. $7 E$; $t$ test, $p<0.05$ ). These results indicate a broad and lasting recovery of rod and circuit functions in Cngb1 rescued mice.

\section{Discussion}

In contrast to other neurons, rods and cones are depolarized in darkness and tonically release glutamate through ribbon synapses (Molday and Moritz, 2015), leading to saturation of rod-to-rod bipolar cell synapses (Sampath and Rieke, 2004). Light exposure causes graded hyperpolarization of the photoreceptor cell and suppression of glutamate release. Reductions in glutamate release from photoreceptors that occur during the early process of retinal degeneration lead to homeostatic changes in the downstream neurons and degrade the retinal circuit. This is seen in the dissolution of synaptic structures, dendritic sprouting, formation of ectopic contacts, and gliosis (Marc et al., 2003; Puthussery and Taylor, 2010). Although strategies to rescue and restore function in defective photoreceptors have shown success for regaining some visual function, gene and stem cell therapies for visual restoration are often implemented in the adult; how well these rescued neurons reinstate their detailed circuitries in the remodeled retina is not known. Here we examined functional restoration at the level of inner retinal cells and defined rod-driven circuits in the young adult mouse retina. We show that repairing a primary genetic defect in rods not only restored rod function, but also recovered normal synaptic connectivity with remodeled second order rod bipolar cells.

\section{Rod-to-rod bipolar cell synaptic contacts are reduced in $\mathrm{Cngbl}^{\text {neo/neo }}$ retina resulting in disrupted synaptic transmission} The relatively slow photoreceptor degeneration we observe in the Cngb $1^{\text {neo/neo }}$ mouse model, and observed in human patients (Bareil et al., 2001; Biel and Michalakis, 2007), may be because of the fact that it is not a functional null. A small but measurable light response persisted in $C n g b 1^{\text {neo/neo }}$ rods from $1 \mathrm{MO}$ mice (Fig. 4A). The residual light response is probably because of the presence of homomeric channels composed of CNGA1 subunits, which are capable of mediating a diminished and desensitized cGMPdependent current (Kaupp et al., 1989). The small current would reduce $\mathrm{Ca}^{2+}$ influx to the outer segment, causing increased levels of cGMP through stimulation of guanylyl cyclases by $\mathrm{Ca}^{2+}$-free guanylyl cyclase activating proteins 1 and 2 (Mendez et al., 2001; Dizhoor et al., 2010). Elevated cGMP has been shown to be a driver of rod degeneration through activation of protein kinase $G$ (Ma et al., 2015; T. Wang et al., 2017).

In addition to the diminished rod light responses in the $C n g b 1^{\text {neo/neo }}$ mice, we observed further desensitization of the ERG b-wave reflecting deficiencies in synaptic transmission. This observation was not unexpected, especially given our ultrastructural evidence showing that the number of triads in the $C n g b 1^{\text {neo/neo }}$ rod spherules was significantly reduced, but not fully eliminated (Figs. 1, 5E). Additionally, a considerable number of dysmorphic spherules were observed in electron micrographs from the $C n g b 1^{\text {neo/neo }}$ retinas. The total lack of light-evoked responses as measured by patch-clamp recordings from rod bipolar cells, even for bright flashes delivering $\sim 2000 \mathrm{Rh}^{\star} / \operatorname{rod}$ (Fig. 6C), is somewhat surprising. Perhaps when assessed at the level of single rod bipolar cells the loss of rods within their receptive fields (or dysmorphic rods within their receptive field) causes tremendous desensitization. We speculate that this defect in synaptic transmission is exacerbated by diminished glutamate release at the ribbon synapse given that the lack of CNG channels which should act as a source of "equivalent light", similar to light-induced closure of CNG channels (Sampath and Rieke, 2004; Dunn et al., 2006). Supporting this idea, the resting membrane potential of $C n g b 1^{\text {пео/nеo }}$ rods are $\sim 10 \mathrm{mV}$ hyperpolarized because of their smaller dark current (Fig. 4A). At the rod's normal resting potential in darkness $(\sim 40 \mathrm{mV})$, calcium enters through the voltage gated channel $\left(\mathrm{Ca}_{\mathrm{v}} 1.4\right)$ and supports tonic glutamate release at the ribbon synapse (Waldner et al., 2018). Thus the hyperpolarizing shift in resting potential of $C n g b 1^{\text {neo/neo }}$ rods predicts attenuated glutamate release from the rod spherule.

Interestingly, suppression of glutamate release at the rod synapse is strongly correlated with synaptic remodeling. Examples include blockade of glutamate release by tetanus toxin (Cao et al., 2015), in knock-out mice that lack the presynaptic $\mathrm{Ca}_{\mathrm{V}} 1.4 \mathrm{Ca}^{2+}$ channel (Mansergh et al., 2005), and in human patients diagnosed with congenital stationary night blindness (CSNB2) that harbor null mutations in the gene encoding $\mathrm{Ca}_{\mathrm{V}} 1.4$ (BechHansen et al., 1998; Boycott et al., 2000). Calcium entry through $\mathrm{Ca}_{\mathrm{V}} 1.4$ channel is required for neurotransmitter release at the ribbon synapse of both rods and cones. The absence of CaBP4 (Haeseleer et al., 2004) or $\alpha 2 \delta 4$ (Y. Wang et al., 2017) that bind and regulate the activity of $\mathrm{Ca}_{\mathrm{V}} 1.4$, also manifest in retinal remodeling in knock-out mice. These plastic changes occurred with minimal photoreceptor cell loss, suggesting that synaptic remodeling is likely driven by suppression of neural transmission, or deafferentation, rather than photoreceptor cell death per se. Modest synaptic changes were also observed in RIBEYE knock-out retinas. RIBEYE is an essential component of the synaptic ribbon, and its absence abolished all presynaptic ribbons in the retina and severely impaired fast and sustained neurotransmitter release (Maxeiner et al., 2016). Spontaneous miniature release continues to occur without the synaptic ribbon, which may explain the milder retinal remodeling phenotype observed in the RIBEYE knock-out retina (Maxeiner et al., 2016).

\section{Adult rod bipolar cells demonstrate plastic changes to establish functional contacts with rescued rods}

The developmental time window for the formation of the rod to rod bipolar cell synapse in mice appears to be from eye opening to P30, during which synaptic proteins are expressed, presynaptic and postsynaptic molecular complexes form, and the rod bipolar 
cells develop the appropriate number of dendritic tips that make synaptic contacts with rods (Anastassov et al., 2019). Some of the molecules that guide neurite growth during development are absent at maturity (D'Orazi et al., 2014), and if functional connectivity of the neural retina can only occur during a critical period in development, then one would expect that the adult retina may lack the ability to make such connections when rod activity is switched on after this time window. Such developmental processes would have been disrupted in $\mathrm{Cngb}^{\text {neo/neo }}$ retinas, wherein pronounced retinal remodeling is observed by P14 (data not shown) and evident by P30 (Fig. 1). We show that tamoxifeninduced CNGB1 expression between P28 and P34 led to establishment of the rod's circulating current in darkness and normal light responses (Fig. 4). Concomitantly, structural changes were observed at the synapse: rod bipolar cells elaborated fine dendritic tips, mGluR6 receptors clustered on these tips which came in close contact with presynaptic ribbons (Fig. 5C). At the ultrastructural level, the number of synaptic triads significantly increased, and dysmorphic structures common in $C n g b 1^{\text {neo/neo }}$ rod spherules were no longer visible (Fig. $5 D, E$ ). These newly formed synaptic structures supported normal neural transmission, as shown by ERG recordings and patch recordings from rod bipolar cells (Fig. 6), and increased light sensitivity in RGCs (Fig. 7). We hypothesize that these changes may be initiated by glutamate release at the rod's synapse, similar to that which occurs at the cortex, where focal uncaging of glutamate in mouse cortical layer $2 / 3$ pyramidal neurons triggered spinogenesis from the dendrite shaft in a location-specific manner (Kwon and Sabatini, 2011).

Plasticity at the photoreceptor/bipolar cell synapse has also been observed in a model of photocoagulation of rabbit retina, where the laser ablation acutely removes a patch of photoreceptors while leaving the inner retina intact (Beier et al., 2017). After some days, nearby photoreceptors slowly migrate toward and fill in the lesioned area (Sher et al., 2013). As they do so, they form functional contacts with the deafferented bipolar cells (Sher et al., 2013; Beier et al., 2017). Another example of plasticity at the photoreceptor/bipolar cell synapse is the AAV-mediated gene therapy to replace retinoschisin (RS1) in adult mice (Ou et al., 2015). Retinal development of the RS1 knock-out mice appears to proceed normally. However, the absence of RS1, a cell adhesion protein, eventually causes splitting of the retina and a failure of synaptic maintenance that manifests in reduction of the ERG b-wave amplitude (Sikkink et al., 2007). This defect was reversed upon RS1 gene replacement (Ou et al., 2015). The molecular pathways that regulate retinal plasticity are poorly defined but are likely specific to different synaptic contacts. For example, plasticity of OFF bipolar cells is regulated by Dscam (Simmons et al., 2017). Here we demonstrate that activation of rod input in young adults reversed synaptic changes that occurred during development. The newly functional rods established functional contacts with their downstream neurons in the retinal circuitry of the adult retina. These results support the therapeutic potential of repairing or replacing defective rods in the degenerating retina. However, a critical time window for rescue likely exists: recent clinical trials for Leber congenital amaurosis (LCA) to replace RPE65 in human patients for treating a type of LCA caused by RPE65 mutations show limited success in visual improvement, and the retina continued to degenerate in some patients (Cideciyan et al., 2013). Future experimentation will address whether a critical time window of rescue exists for these approaches.

\section{References}

Anastassov IA, Wang W, Dunn FA (2019) Synaptogenesis and synaptic protein localization in the postnatal development of rod bipolar cell dendrites in mouse retina. J Comp Neurol 527:52-66.

Bareil C, Hamel CP, Delague V, Arnaud B, Demaille J, Claustres M (2001) Segregation of a mutation in CNGB1 encoding the beta-subunit of the rod cGMP-gated channel in a family with autosomal recessive retinitis pigmentosa. Hum Genet 108:328-334.

Bech-Hansen NT, Naylor MJ, Maybaum TA, Pearce WG, Koop B, Fishman GA, Mets M, Musarella MA, Boycott KM (1998) Loss-of-function mutations in a calcium-channel alphal-subunit gene in Xp11.23 cause incomplete X-linked congenital stationary night blindness. Nat Genet 19:264-267.

Beier C, Hovhannisyan A, Weiser S, Kung J, Lee S, Lee DY, Huie P, Dalal R, Palanker D, Sher A (2017) Deafferented adult rod bipolar cells create new synapses with photoreceptors to restore vision. J Neurosci 37: 4635-4644.

Bermingham-McDonogh O, Reh TA (2011) Regulated reprogramming in the regeneration of sensory receptor cells. Neuron 71:389-405.

Biel M, Michalakis S (2007) Function and dysfunction of CNG channels: insights from channelopathies and mouse models. Molecular neurobiology 35:266-277.

Boycott KM, Pearce WG, Bech-Hansen NT (2000) Clinical variability among patients with incomplete X-linked congenital stationary night blindness and a founder mutation in CACNA1F. Can J Ophthalmol 35: 204-213.

Cao Y, Sarria I, Fehlhaber KE, Kamasawa N, Orlandi C, James KN, Hazen JL, Gardner MR, Farzan M, Lee A, Baker S, Baldwin K, Sampath AP, Martemyanov KA (2015) Mechanism for selective synaptic wiring of rod photoreceptors into the retinal circuitry and its role in vision. Neuron 87 $1248-1260$

Chang B, Hawes NL, Pardue MT, German AM, Hurd RE, Davisson MT, Nusinowitz S, Rengarajan K, Boyd AP, Sidney SS, Phillips MJ, Stewart RE, Chaudhury R, Nickerson JM, Heckenlively JR, Boatright JH (2007) Two mouse retinal degenerations caused by missense mutations in the betasubunit of rod cGMP phosphodiesterase gene. Vision Res 47:624-633.

Chen J, Woodruff ML, Wang T, Concepcion FA, Tranchina D, Fain GL (2010) Channel modulation and the mechanism of light adaptation in mouse rods. J Neurosci 30:16232-16240.

Chichilnisky EJ, Rieke F (2005) Detection sensitivity and temporal resolution of visual signals near absolute threshold in the salamander retina. J Neurosci 25:318-330.

Chua J, Fletcher EL, Kalloniatis M (2009) Functional remodeling of glutamate receptors by inner retinal neurons occurs from an early stage of retinal degeneration. J Comp Neurol 514:473-491.

Cideciyan AV, Jacobson SG, Beltran WA, Sumaroka A, Swider M, Iwabe S, Roman AJ, Olivares MB, Schwartz SB, Komáromy AM, Hauswirth WW, Aguirre GD (2013) Human retinal gene therapy for leber congenital amaurosis shows advancing retinal degeneration despite enduring visual improvement. Proc Natl Acad Sci U S A 110:E517-E525.

Concepcion F, Chen J (2010) Q344ter mutation causes mislocalization of rhodopsin molecules that are catalytically active: a mouse model of Q344ter-induced retinal degeneration. PLoS One 5:e10904.

Cook NJ, Molday LL, Reid D, Kaupp UB, Molday RS (1989) The cGMPgated channel of bovine rod photoreceptors is localized exclusively in the plasma membrane. J Biol Chem 264:6996-6999.

Dacheux RF, Raviola E (1986) The rod pathway in the rabbit retina: a depolarizing bipolar and amacrine cell. J Neurosci 6:331-345.

Dizhoor AM, Olshevskaya EV, Peshenko IV (2010) $\mathrm{Mg}^{2+} / \mathrm{Ca}^{2+}$ cation binding cycle of guanylyl cyclase activating proteins (GCAPs): role in regulation of photoreceptor guanylyl cyclase. Mol Cell Biochem 334:117124.

D’Orazi FD, Suzuki SC, Wong RO (2014) Neuronal remodeling in retinal circuit assembly, disassembly, and reassembly. Trends Neurosci 37:594603.

Dunn FA, Doan T, Sampath AP, Rieke F (2006) Controlling the gain of rod-mediated signals in the Mammalian retina. J Neurosci 26:3959-3970.

Farber DB, Lolley RN (1974) Cyclic guanosine monophosphate: elevation in degenerating photoreceptor cells of the $\mathrm{C} 3 \mathrm{H}$ mouse retina. Science 186:449-451

Field GD, Rieke F (2002) Nonlinear signal transfer from mouse rods to bipolar cells and implications for visual sensitivity. Neuron 34:773-785. 
Field GD, Sampath AP (2017) Behavioural and physiological limits to vision in mammals. Philos Trans R Soc Lond B Biol Sci 372:20160072.

Field GD, Gauthier JL, Sher A, Greschner M, Machado TA, Jepson LH, Shlens J, Gunning DE, Mathieson K, Dabrowski W, Paninski L, Litke AM, Chichilnisky EJ (2010) Functional connectivity in the retina at the resolution of photoreceptors. Nature 467:673-677.

Garg A, Yang J, Lee W, Tsang SH (2017) Stem cell therapies in retinal disorders. Cells 6:E4

Gilliam JC, Chang JT, Sandoval IM, Zhang Y, Li T, Pittler SJ, Chiu W, Wensel TG (2012) Three-dimensional architecture of the rod sensory cilium and its disruption in retinal neurodegeneration. Cell 151:1029-1041.

Granit R (1933) The components of the retinal action potential in mammals and their relation to the discharge in the optic nerve. J Physiol 77:207-239.

Grunwald ME, Yu WP, Yu HH, Yau KW (1998) Identification of a domain on the beta-subunit of the rod cGMP-gated cation channel that mediates inhibition by calcium-calmodulin. J Biol Chem 273:9148-9157.

Haeseleer F, Imanishi Y, Maeda T, Possin DE, Maeda A, Lee A, Rieke F, Palczewski K (2004) Essential role of $\mathrm{Ca}^{2+}$-binding protein 4, a Cav1.4 channel regulator, in photoreceptor synaptic function. Nat Neurosci 7:1079-1087.

Hayashi S, McMahon AP (2002) Efficient recombination in diverse tissues by a tamoxifen-inducible form of cre: a tool for temporally regulated gene activation/inactivation in the mouse. Dev Biol 244:305-318.

Hoyo NL, López-Begines S, Rosa JL, Chen J, Méndez A (2014) Functional EF-hands in neuronal calcium sensor GCAP2 determine its phosphorylation state and subcellular distribution in vivo, and are essential for photoreceptor cell integrity. PLoS Genet 10:e1004480.

Hüttl S, Michalakis S, Seeliger M, Luo DG, Acar N, Geiger H, Hudl K, Mader R, Haverkamp S, Moser M, Pfeifer A, Gerstner A, Yau KW, Biel M (2005) Impaired channel targeting and retinal degeneration in mice lacking the cyclic nucleotide-gated channel subunit CNGB1. J Neurosci 25:130-138.

Kaupp UB, Niidome T, Tanabe T, Terada S, Bönigk W, Stühmer W, Cook NJ, Kangawa K, Matsuo H, Hirose T, Miyata T, Numa S (1989) Primary structure and functional expression from complementary DNA of the rod photoreceptor cyclic GMP-gated channel. Nature 342:762-766.

Koch S, Sothilingam V, Garcia Garrido M, Tanimoto N, Becirovic E, Koch F, Seide C, Beck SC, Seeliger MW, Biel M, Mühlfriedel R, Michalakis S (2012) Gene therapy restores vision and delays degeneration in the CNGB1(-/-) mouse model of retinitis pigmentosa. Hum Mol Genet 21:4486-4496.

Kwon HB, Sabatini BL (2011) Glutamate induces de novo growth of functional spines in developing cortex. Nature 474:100-104.

LaVail MM (1973) Kinetics of rod outer segment renewal in the developing mouse retina. J Cell Biol 58:650-661.

Ma H, Butler MR, Thapa A, Belcher J, Yang F, Baehr W, Biel M, Michalakis S, Ding XQ (2015) cGMP/protein kinase G signaling suppresses inositol 1,4,5-trisphosphate receptor phosphorylation and promotes endoplasmic reticulum stress in photoreceptors of cyclic nucleotide-gated channel-deficient mice. J Biol Chem 290:20880-20892.

Mansergh F, Orton NC, Vessey JP, Lalonde MR, Stell WK, Tremblay F, Barnes S, Rancourt DE, Bech-Hansen NT (2005) Mutation of the calcium channel gene Cacnalf disrupts calcium signaling, synaptic transmission and cellular organization in mouse retina. Hum Mol Genet 14:30353046.

Marc RE, Jones BW (2003) Retinal remodeling in inherited photoreceptor degenerations. Mol Neurobiol 28:139-147.

Marc RE, Jones BW, Watt CB, Strettoi E (2003) Neural remodeling in retinal degeneration. Prog Retin Eye Res 22:607-655.

Maxeiner S, Luo F, Tan A, Schmitz F, Südhof TC (2016) How to make a synaptic ribbon: RIBEYE deletion abolishes ribbons in retinal synapses and disrupts neurotransmitter release. EMBO J 35:1098-1114.

Mendez A, Burns ME, Sokal I, Dizhoor AM, Baehr W, Palczewski K, Baylor DA, Chen J (2001) Role of guanylate cyclase-activating proteins (GCAPs) in setting the flash sensitivity of rod photoreceptors. Proc Natl Acad Sci U S A 98:9948-9953.

Moaven H, Koike Y, Jao CC, Gurevich VV, Langen R, Chen J (2013) Visual arrestin interaction with clathrin adaptor AP-2 regulates photoreceptor survival in the vertebrate retina. Proc Natl Acad Sci U S A 110:9463-9468.

Molday RS, Moritz OL (2015) Photoreceptors at a glance. J Cell Sci 128:4039-4045.

Ou J, Vijayasarathy C, Ziccardi L, Chen S, Zeng Y, Marangoni D, Pope JG,
Bush RA, Wu Z, Li W, Sieving PA (2015) Synaptic pathology and therapeutic repair in adult retinoschisis mouse by AAV-RS1 transfer. J Clin Invest 125:2891-2903.

Pahlberg J, Frederiksen R, Pollock GE, Miyagishima KJ, Sampath AP, Cornwall MC (2017) Voltage-sensitive conductances increase the sensitivity of rod photoresponses following pigment bleaching. J Physiol 595: 3459-3469.

Poetsch A, Molday LL, Molday RS (2001) The cGMP-gated channel and related glutamic acid-rich proteins interact with peripherin-2 at the rim region of rod photoreceptor disc membranes. J Biol Chem 276: 48009-48016.

Puthussery T, Taylor WR (2010) Functional changes in inner retinal neurons in animal models of photoreceptor degeneration. Adv Exp Med Biol 664:525-532.

Quartilho A, Simkiss P, Zekite A, Xing W, Wormald R, Bunce C (2016) Leading causes of certifiable visual loss in england and wales during the year ending 31 march 2013. Eye 30:602-607.

Sampath AP, Rieke F (2004) Selective transmission of single photon responses by saturation at the rod-to-rod bipolar synapse. Neuron 41:431-443.

Saszik SM, Robson JG, Frishman LJ (2002) The scotopic threshold response of the dark-adapted electroretinogram of the mouse. J Physiol 543:899-916.

Scholl HP, Strauss RW, Singh MS, Dalkara D, Roska B, Picaud S, Sahel JA (2016) Emerging therapies for inherited retinal degeneration. Sci Trans Med 8:368rv6.

Sher A, Jones BW, Huie P, Paulus YM, Lavinsky D, Leung LS, Nomoto H, Beier C, Marc RE, Palanker D (2013) Restoration of retinal structure and function after selective photocoagulation. J Neurosci 33:6800-6808.

Sikkink SK, Biswas S, Parry NR, Stanga PE, Trump D (2007) X-linked retinoschisis: an update. J Med Genet 44:225-232.

Simmons AB, Bloomsburg SJ, Sukeena JM, Miller CJ, Ortega-Burgos Y, Borghuis BG, Fuerst PG (2017) DSCAM-mediated control of dendritic and axonal arbor outgrowth enforces tiling and inhibits synaptic plasticity. Proc Natl Acad Sci U S A 114:E10224-E10233.

Soto F, Kerschensteiner D (2015) Synaptic remodeling of neuronal circuits in early retinal degeneration. Front Cell Neurosci 9:395.

Vinberg F, Kolesnikov AV, Kefalov VJ (2014) Ex vivo ERG analysis of photoreceptors using an in vivo ERG system. Vision research 101:108-117.

Vinberg F, Wang T, Molday RS, Chen J, Kefalov VJ (2015) A new mouse model for stationary night blindness with mutant Slc24al explains the pathophysiology of the associated human disease. Human molecular genetics 24:5915-5929.

Waldner DM, Bech-Hansen NT, Stell WK (2018) Channeling vision: CaV1.4-A critical link in retinal signal transmission. Biomed Res Int 2018:7272630.

Wang T, Chen J (2014) Induction of the unfolded protein response by constitutive G-protein signaling in rod photoreceptor cells. J Biol Chem 289:29310-29321.

Wang T, Tsang SH, Chen J (2017) Two pathways of rod photoreceptor cell death induced by elevated cGMP. Hum Mol Genet 26:2299-2306.

Wang X, Zhao L, Zhang Y, Ma W, Gonzalez SR, Fan J, Kretschmer F, Badea TC, Qian HH, Wong WT (2017) Tamoxifen provides structural and functional rescue in murine models of photoreceptor degeneration. J Neurosci 37:3294-3310.

Wang Y, Fehlhaber KE, Sarria I, Cao Y, Ingram NT, Guerrero-Given D, Throesch B, Baldwin K, Kamasawa N, Ohtsuka T, Sampath AP, Martemyanov KA (2017) The auxiliary calcium channel subunit $\alpha 2 \delta 4$ is required for axonal elaboration, synaptic transmission, and wiring of rod photoreceptors. Neuron 93:1359-1374.e6.

Yao K, Qiu S, Wang YV, Park SJH, Mohns EJ, Mehta B, Liu X, Chang B, Zenisek D, Crair MC, Demb JB, Chen B (2018) Restoration of vision after de novo genesis of rod photoreceptors in mammalian retinas. Nature 560:484-488.

Yu WQ, Grzywacz NM, Lee EJ, Field GD (2017) Cell type-specific changes in retinal ganglion cell function induced by rod death and cone reorganization in rats. J Neurophysiol 118:434-454.

Zhang Y, Molday LL, Molday RS, Sarfare SS, Woodruff ML, Fain GL, Kraft TW, Pittler SJ (2009) Knock-out of GARPs and the beta-subunit of the rod cGMP-gated channel disrupts disk morphogenesis and rod outer segment structural integrity. J Cell Sci 122:1192-1200. 